\title{
A Review on Synthesis of Nitrogen-containing Heterocyclic Dyes for Textile Fibers - Part 1: Five and Six-membered Heterocycles
}

\author{
Tawfik A. Khattab ${ }^{1^{*}}$ and Mohamed Rehan ${ }^{2}$ \\ ${ }^{1}$ Dyeing, Printing and Auxiliaries Department, Textile Industries Research Division- \\ National Research Centre, 33 El-Buhouth Street, Dokki, Cairo 12622, Egypt. \\ ${ }^{2}$ Department of Pretreatment and Finishing of Cellulosic Fibers, Textile Industries \\ Research Division National Research Centre, 33 El-Buhouth Street, Dokki, Cairo \\ 12622, Egypt.
}

$\mathbf{T}$ HE SIGNIFICANCE of heterocyclic dyestuffs has recently increased due to their deep hues and brightness, high color strength and better colorfastness compared to benzene analogous dyes. In this review, we give details outlining the synthetic approaches of all recently synthesized nitrogen-containing five and six-membered ring heterocyclic dyestuffs and their dyeing efficiency on textile fibers.

Keywords: Nitrogen heteroatom, Heterocyclic, Dyes, Synthesis, Dyeing, Fabric.

\section{Introduction}

The former synthetic dyestuff, Mauveine, was recognized by Perkin in 1850s [1]. Dyes have become indispensable tools for a variety of applications [2]. For instance, they act as colorants for plastics, paper, ceramics, coatings, constructions, textiles and other highly sophisticated technology purposes [1-8]. Dyes are also used in sensors, inks, tinting, adhesives, beverages, cosmetics, foodstuff, polymers, optical data storage, leather, and wax biomedicine [9-22]. Dyes that are employed for textiles dyeing often come with particular properties that include color fastness to sublimation, light, wash, perspiration and rubbing. Dyes used in textile industry can currently be described as mature. Nonetheless, it stays a vibrant and challenging field which necessitates a continuous production of novel materials due to the fast changing global customers' requirements. Several types of dye used today were recognized in 1800s $[1,2]$. However, the oil crisis in 1970s led to a sharp increase in the cost of raw materials for dyestuffs. This generated a force toward lower cost dyestuffs by enhancing the efficiency of the procedures and by replacing dyestuffs of low tinctorial strength, such as anthraquinone-based dyes, by tinctorially stronger dyes, such as heterocyclic-based benzofuranone and azo dyes. These subject matters are still significant and continuing, as are the modern matters of merchandise safety, quality, and environmental protection [2]. Therefore, a variety of dyes have been reported. Dyestuffs can be classified according to their structure or according to end-use application on a certain substrate [23]. For instance, the disperse dyestuffs are characterized by a variety of chemical structures such as monoazo 1 [24], anthraquinone 2 [25] and disazo 3 [26] structures (Fig. 1) and they are applied on hydrophobic substrates such as polyester fibers.

Heterocyclic-based materials are pervasive in various fields of life sciences [27-35]. Heterocyclic dyes have been utilized in many fields, such as inkjet printing, photovoltaics, photography, digital optical storage, photodynamic therapy, bioimaging $[2,6$, 12, 36-38]. Azo dyestuffs are now used to generate nearly the whole range of color shades. For instance, the anthraquinone derivatives of azo dyes are usually employed for red, blue, violet and turquoise shades, while other azo derivatives are used mostly to manufacture yellow shades [2]. A long-term target of dyestuffs research has been to merge both brightness and colorfastness properties of anthraquinone-based dyestuffs with the color strength and low cost of azo-based dyestuffs. This target is currently being recognized with heterocyclic-based azo dyestuffs, which can be divided into two major classes depending on the different chemical structures of the heterocyclic coupling moieties and the heterocyclic diazo moieties. All heterocyclic coupling moieties that offer commercially significant azo dyestuffs enclose mainly nitrogen heteroatom, such as indoles 4, pyrazolones 5, and in particular pyridones 6; (Fig. 2) which afford yellow to orange shades on various substrates [2, 39]. 
<smiles>Cn1c(=O)c(N=Nc2cccc([N+](=O)[O-])c2)c(O)c2ccccc21</smiles>

C.I. Disperse Yellow 5

1<smiles>[R]n1c(=O)c2c(N)c3c(=O)c4ccccc4c(=O)c3c(N)c2c1=O</smiles>

Turquoise $\mathrm{R}=$ alkyl<smiles>Cc1c(N=Nc2ccc(N=Nc3ccccc3)cc2)c(O)n(C)c(=O)c1C#N</smiles>

Fig. 1. Chemical structures of the disperse dyestuffs.

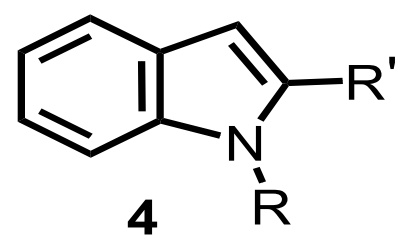<smiles></smiles><smiles>[R]c1c(C)cc(O)n([R])c1=O</smiles>

Fig. 2. Chemical structures of the azo dyes contain mainly nitrogen heteroatom.

Many dyes of yellow shade were of azopyrazolones, howeverthose have currentlybeen mostly replaced by azopyridones. Azopyridone dyestuffs of yellow shades are characterized by better brightness and color strength, and commonly possess better colorfastness properties than azopyrazolones. Both of azopyrazolones and azopyridones are usually exist in the hydrazone form. Typical examples include azopyrazolone C.I. Acid Yellow 237 and azopyridone $8[40,41]$ (Fig. 3). In this review, the five and six-nitrogen containing heterocyclic dyes will be divided according to the number of atoms building the heterocyclic ring and the number of nitrogen heteroatoms included in their molecular structure.<smiles>O=C(O)C1=NN(c2ccc(S(=O)(=O)O)cc2)C(=O)/C1=N\Nc1ccc(S(=O)(=O)O)cc1</smiles><smiles>CCCCN1C(=O)C(C#N)=C(C)/C(=N/Nc2ccc(Cl)cc2)C1=O</smiles>

Fig. 3. Chemical structures of azopyrazolone (7) and azopyridone (8). 


\section{Dye classes}

The sort of dyestuff used to dye technical textiles depends on the fiber characteristics, the target color, color strength, ease of coloration and colorfastness properties demanded by end-users. Some dyestuff types will dye some different fibers, but practically one fiber will dominate. For instance, disperse dyestuffs are mostly employed to dye polyester fibers, although they can also be used to dye nylon, acrylic, and cellulose acetate fibers, but with limits upon the color strength and color fastness properties [2, 42].

\section{Acid dyes}

Acid dyestuffs are anionic in nature with substantivity to proteinic fibers, such as wool, silk, nylon or any further garments containing basic functional groups. Acid dyestuffs are usually applied from an acidic or neutral dye-bath. Acid dyes can be printed onto wool, silk, nylon, and other fibers employing traditional printing thickeners followed steam fixation, washing, and then drying. Acid dyes enclose acidic functional groups, generally sulfonates. Wool, silk and nylon fibers enclose amino functional groups which is protonated in acidic dye-bath to present active basic sites $\left({ }^{+} \mathrm{NH}_{3}\right)$. The acid dye anion $\left(-\mathrm{SO}_{3}^{-}\right)$, is therefore substantive to the fiber and is adsorbed, creating a salt-like bond with the fiber active basic sites. Monosulfonated acid dyestuffs can be adsorbed to a higher level than di-, tri-, or tetrasulfonated acid dyestuffs because the amount of active basic sites on the fibers is restricted by the fiber structure. Therefore, the color strength is usually higher with monosulfonated acid dyestuffs on wool which is characterized by higher active basic sites than nylon and silk. However, the acid dye solubility in water increases upon increasing the number of sulfonate groups [43].

\section{Mordant dyes}

Chrome mordant dyestuffs are the only category of mordant dyes with commercial importance. They are applied in exhaustion dyeing onto wool or irregularly nylon fibers with high color fastness. The fibers are typically dyed by the afterchrome technique in which a chrome dye is applied on fiber followed by additional treatment at $\mathrm{pH} 3.5$ in a next bath be full of potassium or sodium dichromate. The absorption of dichromate anions results in the development of a $1: 1$ and/ or 1 : 2 chromium metal complex dyestuff within the fiber, which results in some troubles in batch-to-batch reproducibility of shade. Low chrome dyeing processes can encourage complete exhaustion of chromium on fibers, reducing water pollution by chromium [44].

\section{Basic dyes}

Basic dyes are cationic colorants with substantivity for acrylic, polyester, and nylon fibers on which basic dyes can introduce brilliant colors. Basic dyes can be used to dye proteinic and cellulose acetate fibers, but their light fastness on hydrophilic fibers is poor. The ionic attraction among the basic dyestuff and the sulfonic acid active sites in acrylic fibers is strong, which affords excellent colorfastness to wash. The closepacked physicochemical character of acrylic fibers and the dye-fiber strong bond can lead to weak migration and leveling, but introduce excellent color fastness against light. Acrylic fibers differ broadly in their dye-ability due to the different quantities of different monomers employed with polyacrylonitrile that adjust the requested glass transition temperature of the fiber. Print fixation is carried out by steam followed by washing, and finally drying [45].

Azoic dyes

Azoic dyes are generated within the fiber typically by adsorption of an aromatic hydroxylbearing substance, such as naphthol as the azoic coupling active agent followed by azo-coupling process with a stabilized aromatic diazonium salt to introduce a colored insoluble dye with azo functional group. The application technique must be performed with care as the ending color is only achieved after soaping off to eliminate any remained traces of the azoic starting components located on the fiber surface that may provide inferior colorfastness to washing and rubbing. Although azoic dyes are inexpensive to introduce red and black colors because their color range is currently more restricted as some diazo compounds prepared from certain aromatic amines have been inhibited due to their probable carcinogenic character [46].

\section{Direct dyes}

Direct dyestuffs were recognized as the former category of synthetic dyestuffs to be applied on cotton fibers directly without mordant. They are sulfonated diazo, trisazo or polyazo anionic colorants with substantivity to cellulosic fibers. Direct dyes containing stilbene, oxazine, copper complex, thiazole and phthalocyanine chemical frameworks were also employed. They have lower color brightness than acid and basic dyes. Phthalocyanines are employed for highly bright 
blue and turquoise-blue colors of excellent colorfastness against light. Copper-complex direct dyestuffs also display high colorfastness to light. An electrolyte, sodium sulphate, is typically included in the dye-bath to defeat the negative charges on cellulose fiber surface which otherwise would resist reaching direct dye anions. The electrolyte sodium ions neutralize the negative charges at the fiber surface, permitting the dyestuff anions to be adsorbed and held onto the fiber. Direct dyestuffs are generally linear and planar molecular frameworks permitting multiple linkages to cellulose polymer chain units, however the attraction forces among dyestuff molecule and fiber are comparatively poor when the dyed fiber is soaked in water. Accordingly, the colorfastness to wash is medium to poor, however the colorfastness to light ranges between excellent to poor relying on the chemical structure of the dye [47].

\section{Reactive dyes}

Reactive dyestuffs are an extremely significant category of colorants for cellulosic and proteinic fibers. Although they are quite expensive, they give a broad series of bright colors of high colorfastness to washing. This is because during the fixation procedure, typically performed in alkaline environment, strong covalent bonding is created among dye and fiber. Reactive dyestuffs may interact via substitution reaction of monochlorotriazinyl- or dichlorotriazinyl-based reactive dyestuffs or via addition reaction of vinylsulfone-containing reactive dyes. Recent developments resulted in the production of homobifunctional-based reactive dyestuffs, such as two monochlorotriazine; and heterobifunctional-based reactive dyestuffs, such as monochlorotriazine in combination with vinylsulfone in order to enhance the dye bonding on the fiber in the alkaline environment (50-70\% for mono-reactive group and $80-95 \%$ for direactive functional groups). The dye application techniques on fibers include exhaustion, cold padbatch or continuous pad-steam. Reactive dyes may hydrolyze in water and in presence of alkali. During the dyeing process, some hydrolyzed reactive dyestuff molecules are absorbed by the fiber because it acts as a substantive direct dyestuff, as but with less colorfastness to wash than the reactive dyestuff that is covalently bounded to the fabric polymer chain units. Therefore, the dyeing steps are usually followed by an extensive wash-off process to eliminate the hydrolyzed reactive dyestuff residues. The high water solubility generates ecological trouble in waste water treatment plants as usually only $0-30 \%$ of the hydrolyzed reactive dyestuffs can be eliminated [48].

Sulfur dyes

Sulphur dyes are produced by heating a variety of aromatic diamines, nitrophenols,...etc, with sulphur and sodium sulphide. Sulphur dyestuffs are formed in an water-insoluble pigment form with no substantive ability to cellulosic fibers. Treating sulfur dyes with a reduction agent such as sodium sulphide or sodium hydrosulphide in presence of an alkali transforms the sulfur dye molecule into the reduced soluble leuco form with high substantive character to cellulose. Once absorbed onto the fiber, the dye molecule is then oxidized, typically using hydrogen peroxide, back to the water-insoluble pigment form. Soaping off, after dyeing, is significant to guarantee the highest colorfastness to washing and rubbing. Sulphur dyes are cheaper than numerous other dyes, however, the waste water from dyeing may necessitate particular treatments before discharge into waste water treatment plants [49].

Vat dyes

Vat dyestuffs are water-insoluble, however they enclose two or more ketone $(>\mathrm{C}=\mathrm{O})$ functional substituents separated by a conjugated molecular structures of double bonds that are reduced to the water-soluble enolate (>C-O-) leuco form. The dye application technique contain three steps, including, alkaline reduction by sodium hydroxide and sodium hydrosulphite, increasing substantivity of leuco form to the fiber, assisted by electrolyte, such as sodium sulphate, and wetting, dispersing and levelling agents, followed by reproduction of the insoluble vat dye within the fiber via oxidation using hydrogen peroxide. The dyed fibers are then thoroughly washed off to remove any surface dye. Vat dye molecular structure range is between indanthrones, flavanthrones, pyranthrones, dibenzanthrones, acylaminoanthraquinones, carbazoles, azoanthraquininones, indigoids and thioindigoids. Vat colorants are comparatively costly but present excellent color fastness properties on cellulose [50,51].

\section{Disperse dyes}

Disperse dyes are water-insoluble colorants of small size molecular structure with substantivity for hydrophobic fibers and are generally applied as a fine aqueous dispersion. The key chemical 
categories are aminoazobenzenes, anthraquinones, nitrodiphenylamines, styryls, quinophthalones, and benzodifuranones. Disperse colorants are pulverized using a dispersing agent. Disperse dyestuffs are basically nonionic compounds usually attracted to hydrophobic fibers, such as polyester and cellulose acetate. The aqueous solubility of disperse dyes is low but increases at high temperature, and consequently raises dyeing rate. The dye solubility can also be increased upon employing levelling agents and carriers. Therefore, the high temperature pressure disperse dyeing at $130^{\circ} \mathrm{C}$, followed by dry thermofixation are usually used. To reduce potential troubles associated with the residual of disperse dyes on the fiber surface after dyeing which result in poor color fastness, reduction clearing is employed after dyeing using sodium hydroxide, sodium hydrosulphite and a surfactant [52].

Pigments

Pigments are water-insoluble synthetic or natural organic or inorganic materials. Inorganic pigments are such as carbon, antimony oxide, titanium, iron and zinc, while organic pigments include a wide range of chemical structures such as azo compounds, anthraquinones, dioxazines, indanthrones, perylenes, quinacridones, copper phthalocyanines, heterocyclic nickel complexes...etc. The pigment particles are ground down to a fine state and stabilized by dispersing agents and stabilizers. Numerous high performance textiles are printed by pigments in order to afford the high performance requirements claimed by end-users [53-55].

Heterocyclic dyes containing 5-membered ring with two nitrogen heteroatoms

Diethyloxalate was reacted with methylamine to afford 9 which then interacted with phosphorus pentachloride to afford 10 [56] followed by nitration and treatment with ammonia to produce 11. Compound 13 [57] was prepared by treating 12 [58] with chlorocyanogen (Scheme 1).

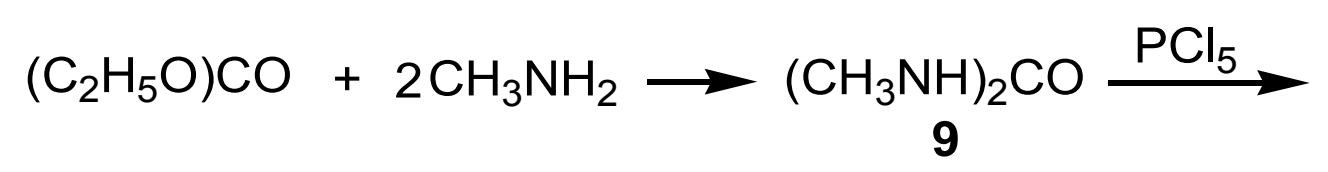<smiles>Cn1cncc1Cl</smiles>

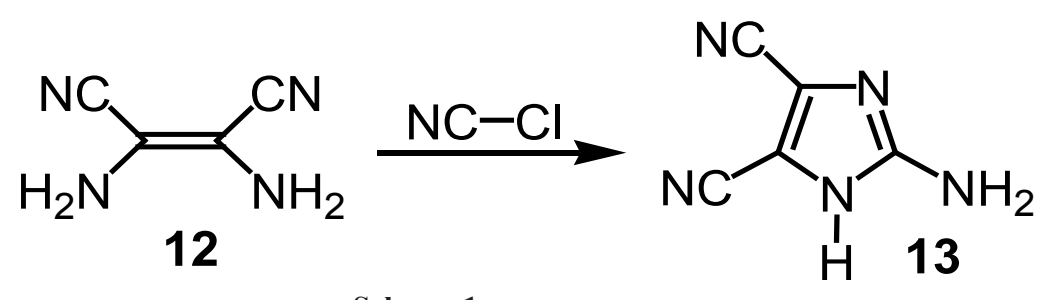

Scheme 1.

Imidazole dyes of red to violet shades with moderate colorfastness, derived from compound 11 were prepared. Bright red dyes having high absorptivity and good light and sublimation fastness on polyester and polyamide fabrics were prepared from the imidazole derivative 13 [59] which was diazotized to produce the corresponding diazonium salt followed by azocoupling with $N$-benzyl- $N$-ethyl- $m$-acetamide aniline to afford 14 [59] (Scheme 2). Such dyes possess poor light fastness which can be improved by alkylation of imidazole ring to produce 15 (Scheme 2) and resulting in bathochromic shift. 


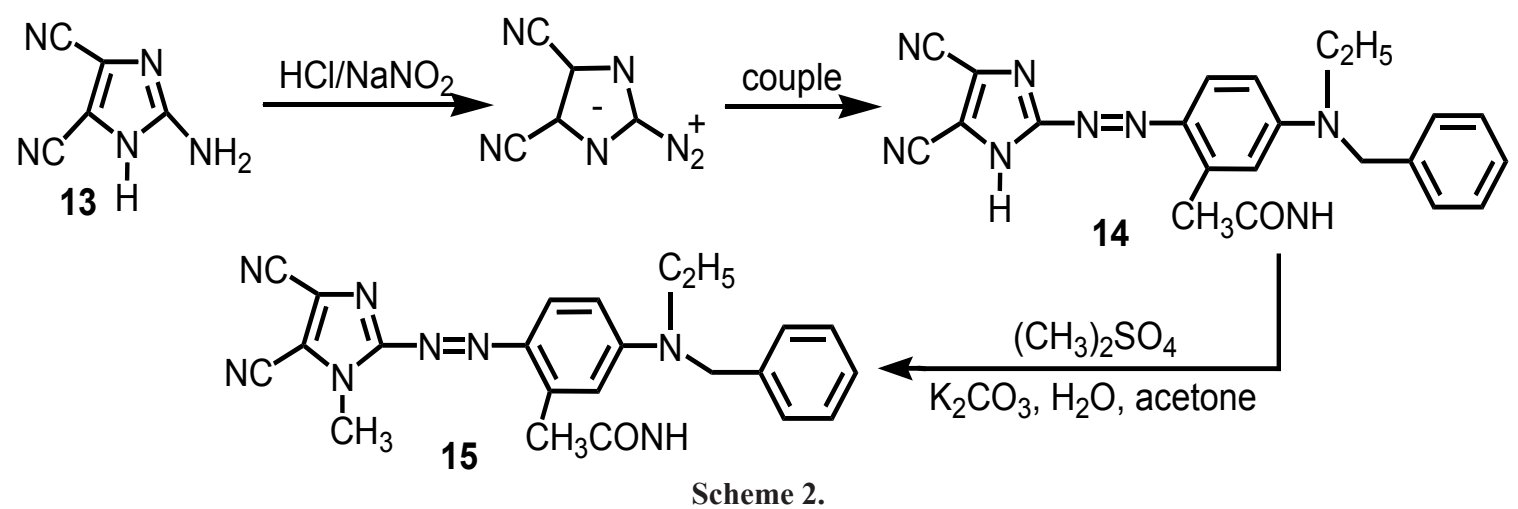

Blue imidazole diazo dyes 18 were prepared from 13 [59] (Scheme 3) using couplers such as 1-naphthylamine giving 16, followed by diazotization procedure and azo-coupling of the intermediate dyestuff 16 and lastly, the diazo dyestuff 17 is alkylated. Coupler containing amino group at the para position to the coupler nitrogen atom is diazotized and transformed into diazocyanide, which was then reacted with o-phenylenediamine to afford 2-benzimidazolylazo dyestuff. Reaction of 19 with hydrazine or its derivatives produced 5 -aminopyrazoles 20 . Reaction of isoxazole 21 with hydrazine produced 22 [60].

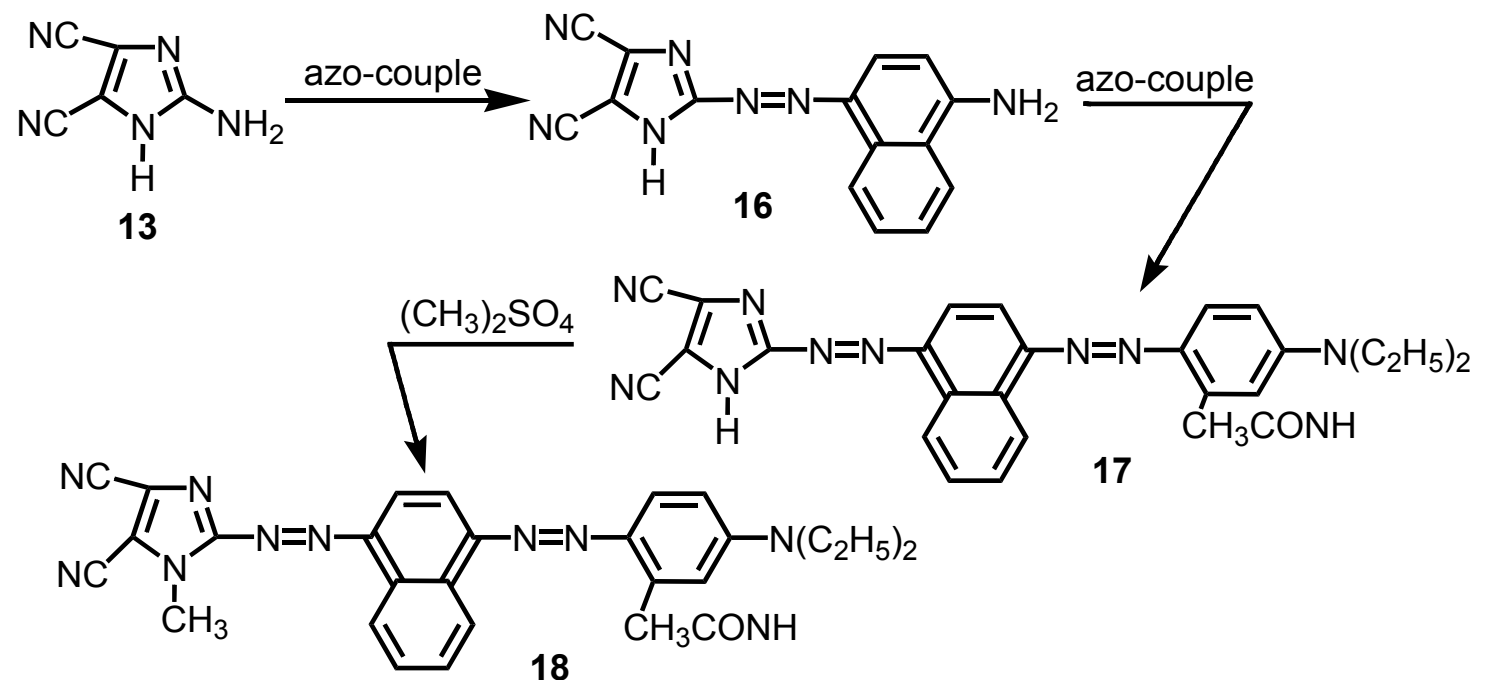

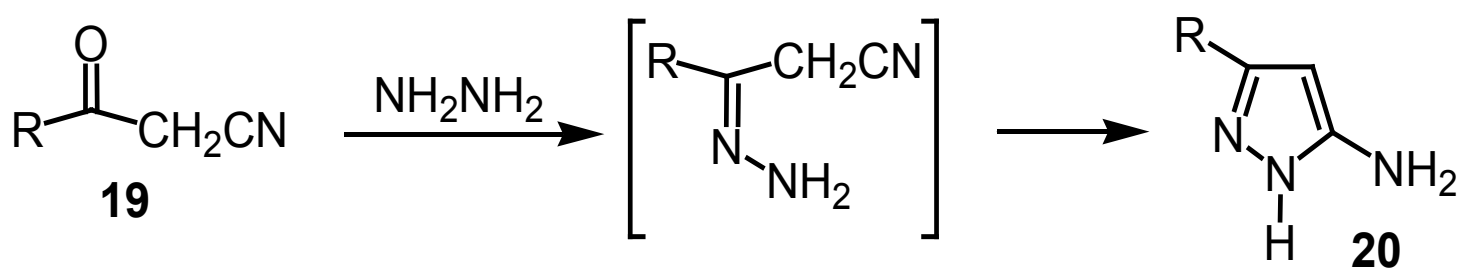<smiles>Cc1oncc1[N+](=O)[O-]</smiles>

21<smiles>CC(=NN)C(C)(CN)[N+](=O)[O-]</smiles>

Scheme 3. 
Cyanopyrazoles 24 [61-63] (Scheme 4) was obtained by condensation of 23 or its C-alkyl or C-aryl analogues, with hydrazine or its derivatives. Compound 26 (Scheme 4) can be synthesized via reacting 25 with hydrazine or substituted hydrazines. 5-Amino-3,4dicyanopyrazoles can be obtained via reaction of tetracyanoethylene with hydrazine [64]. 4-Aryl-5amino-3-trifluoromethylpyrazoles were prepared from the properly substituted hydrazine and $\beta$-ketonitrile. Aminopyrazoles with substituted nitrogen heteroatom were synthesized by reacting phenylhydrazine with acrylonitrile followed by dehydrogenation of the produced pyrazoline.

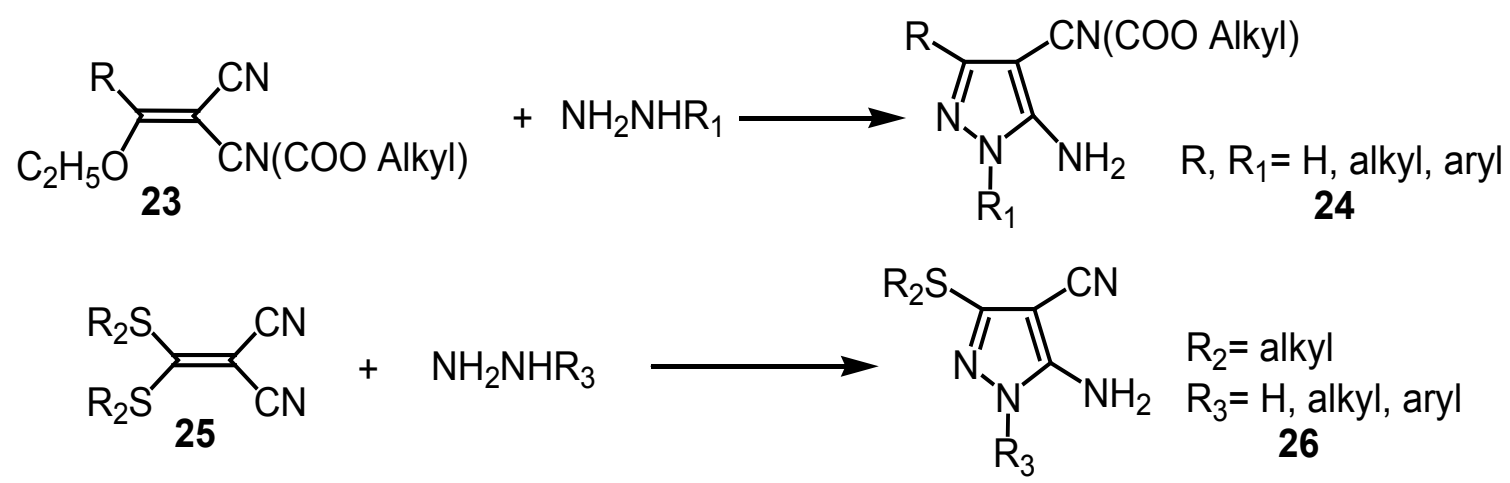

Scheme 4.

Yellow to violet cyano dyes 27 for hydrophobic fibers were prepared from the 5-aminopyrazole derivative 24. Also 27 were prepared by diazotization and coupling of 28 to give the corresponding bromo intermediates 29 which were then converted to 27 via reaction with metal cyanides [12] (Scheme 5). Bright red dyestuffs with good light fastness on polyester fibers are produced in this series of dyestuffs upon using 3'-(N,N-dialkylamino)acylanilide-type as couplers. Yellow dyestuffs are produced when 5-aminopyrazoles are diazotized and azo-coupled with 3-cyano4-alkyl-6-hydroxy-2-pyridone and indole couplers. Acid dyestuffs are synthesized from these diazo moieties with aromatic amine couplers which enclose N-(sulfatoalkyl) functional groups [65].

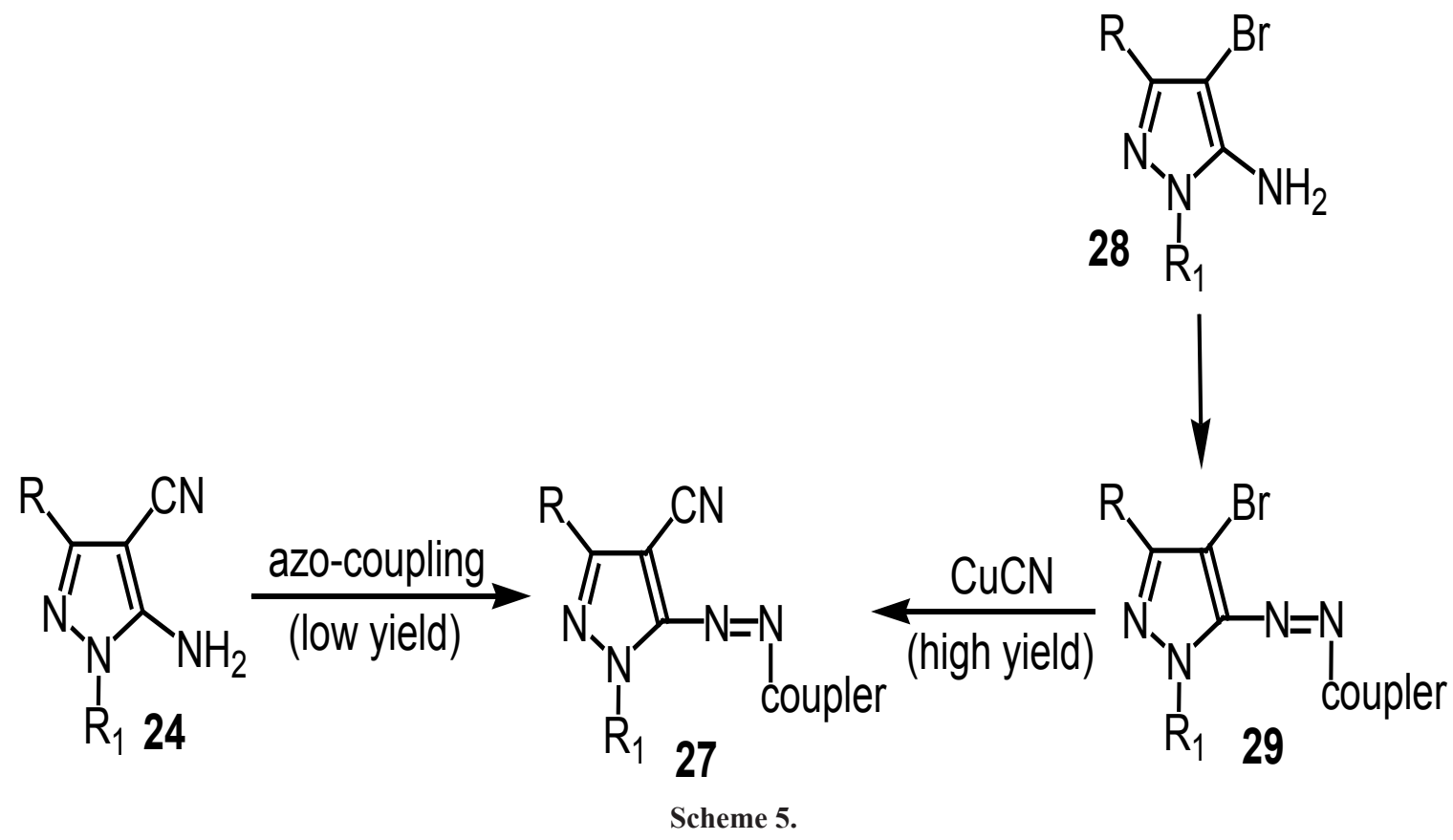

Egypt.J.Chem. 61, No. 5 (2018) 


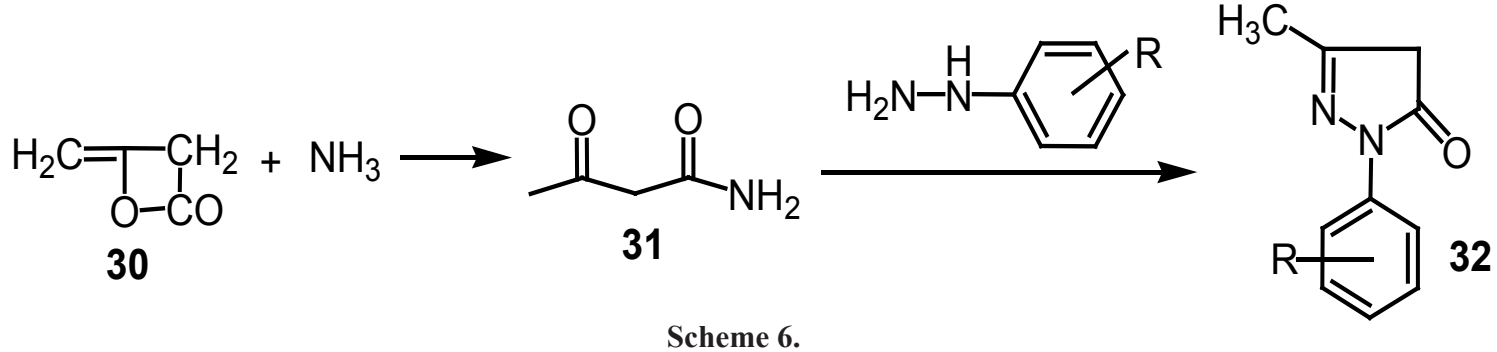

Scheme 6.

The prazolone 32 (Scheme 6) were produced from 31 which were prepared from the diketene 30. Coupling aniline with 32 afforded the hydrazonoprazolone dye 33 [66] (Fig. 4).
Reaction of diacetonitrile, which were obtained by reaction of acetonitrile with sodium metal, with hydrazine afforded the iminopyrazole 34 (Scheme 7).

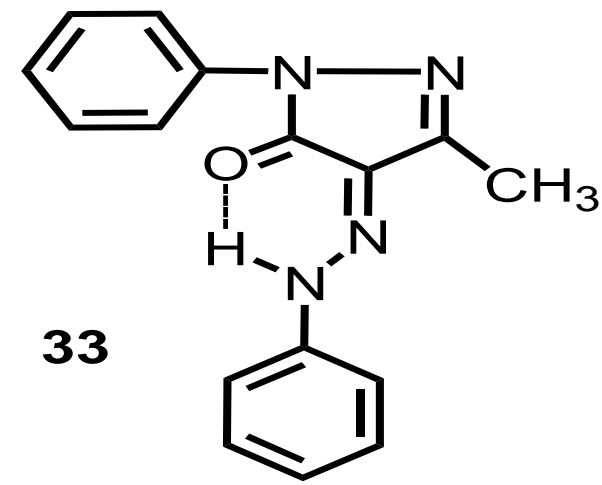

Fig. 4. Chemical structures of the hydrazonoprazolone dye.

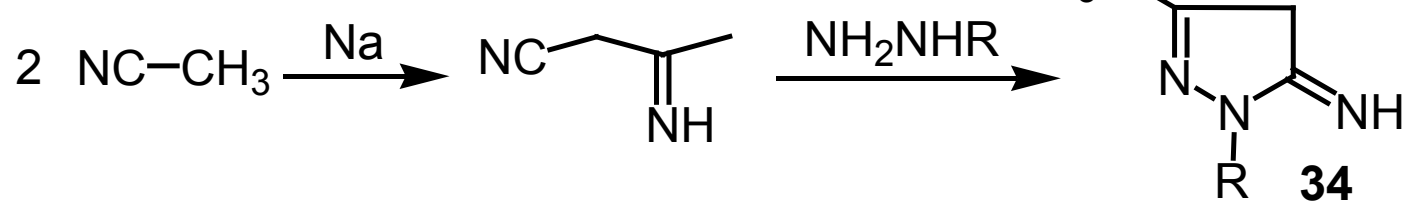

Scheme 7.

Kurtz and Gold described the synthesis of 5-aminopyrazole from propargyl chloride via reaction with hydrogen cyanide to produce propargyl cyanide which was isomerized to cyanoallene and reacted with substituted hydrazine to create the hydrazone form of cyanoacetone. This is followed by ring closure to yield 5-aminopyrazole 35 (Scheme 8).
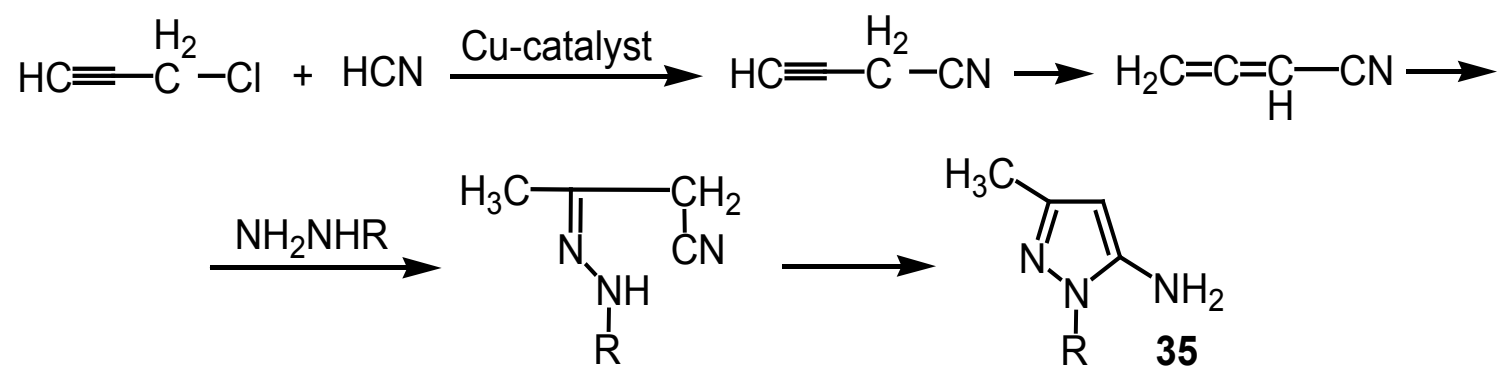

Egypt.J.Chem. 61, No.5 (2018)

Scheme 8. 
5-aminopyrazoles can be azo-coupled in an acidic environment to provide azo dyestuffs 3638 (Scheme 9). They are significant to produce very bright greenish-yellow shades of good light fastness and good migration, especially on wool, polyamide and acrylic fibers.
Imidazole was used as coupling component to give 39 which was quaternized to 40 followed by reaction with secondary amine [67] leading to the corresponding azacyanine dyes 41. Dyestuffs 41 were characterized by brilliant red shades on acrylic fibers with good light fastness and good migration [68] (Scheme 10).<smiles>Cc1nn(-c2ccccc2)c(N)c1N=Nc1cc(Cl)c(S(=O)(=O)O)cc1Cl</smiles><smiles>[X][N+](C)(C)CC(=O)c1ccc(N=Nc2c(C)nn(-c3ccccc3)c2N)cc1</smiles>

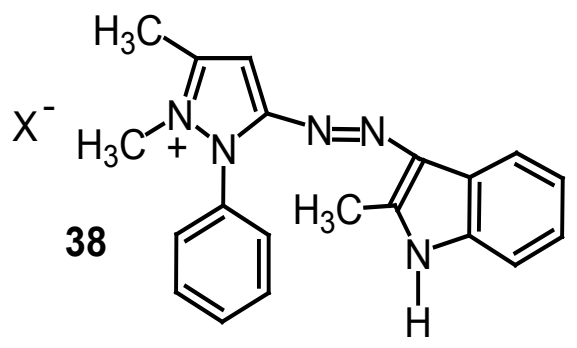

Scheme 9.

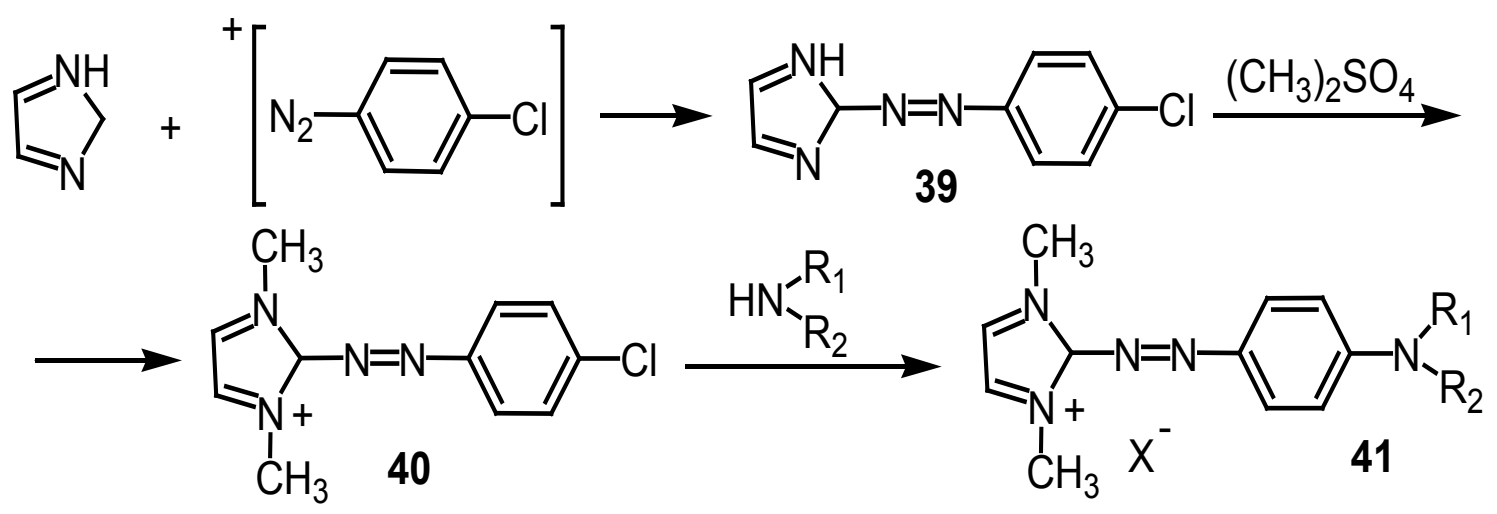

Scheme 10 .

Pyrazol-3-ones were synthesized using biacetyl and primary aromatic amines [69]. Dyes 42 and 43 were obtained by conventional azo-coupling (Fig. 5). The reactivity of pyrazol-3-ones are less than that pyrazol5 -ones in the azo-coupling process [70]. Longer reaction periods (2-3 hours instead of 30 minutes) and higher $\mathrm{pH}$ environment (7-8 instead of 2-3) are required. The pyrazole dye 42 offered greenish-yellow shades with low degree of saturation and decreased lightness.
Disperse dyes of chemical frameworks with suitable substitution patterns; have fairly good characteristics on polyester fibers. Best outcomes were recognized with azo-metal complex derivatives in dyeing of wool fibers. Comparison among pyrazolone isomers is highly favorable to pyrazol-5-one for which colorfastness properties and tinctorial strength always have higher levels than pyrazol-3-one [71]. 


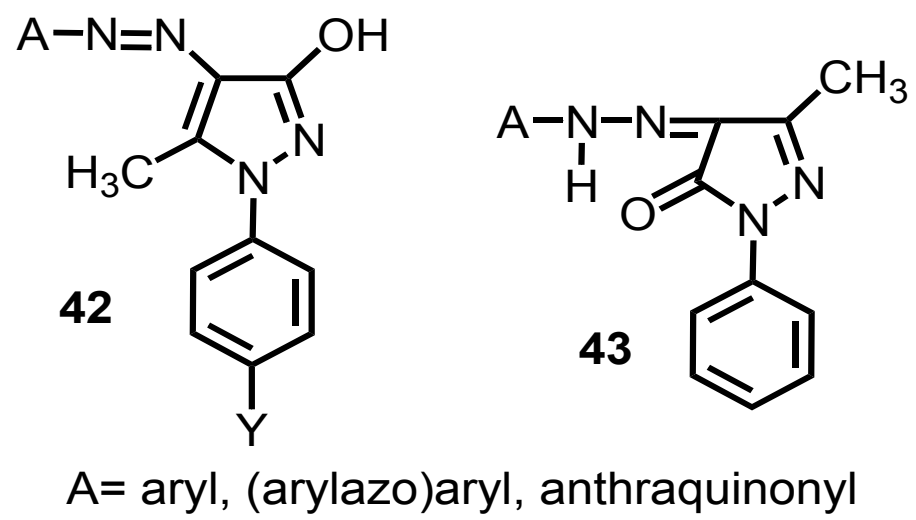

Fig. 5. Chemical structure of the Pyrazol-3-ones.

Diazotized 44 was subjected to azo-coupling with 45 in sodium acetate buffered solution to form 46. Reaction between arene diazonium ions and 46 in presence of sodium hydroxide produced asymmetrical 3-cyanoformazans 47 (Scheme 11).

The derivatives of compounds 46 and 47 were evaluated as direct, acid and basic dyes. The coloration features on cellulose, wool and nylon were mainly satisfactory. All dyeings have very good colorfastness to light, although colorfastness to wash was moderate [72]. The hydrazone dye 48 (Fig. 6) was synthesized via diazotization of $\mathrm{m}$-aminobenzoic acid followed by coupling with N-phenyl-2-methyl-5-pyrazolone.
Dye 48 was reacted with cyclohexylamine or lysine using ethyl chloroformate as an activating agent, to produce and amide compound that can then be reactively dyed on wool and nylon 6.6 affording colorfastness properties which are far superior to those predictable for traditional acid dyeing using carboxy-based derivatives. This indicates considerable fixation of the dye onto the fiber [73].

Yellow acid dyes 49 and 50 (Fig. 7) derived from I-phenyl-3-methyl-5-pyrazolone, were synthesized by diazotization of the proper amines followed by azo-coupling with the pyrazolones in an alkaline environment at $0-5^{\circ} \mathrm{C}$.

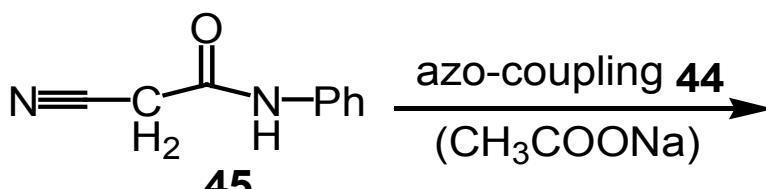
45<smiles>[R]NN=C(C#N)C(=O)Nc1ccccc1</smiles>

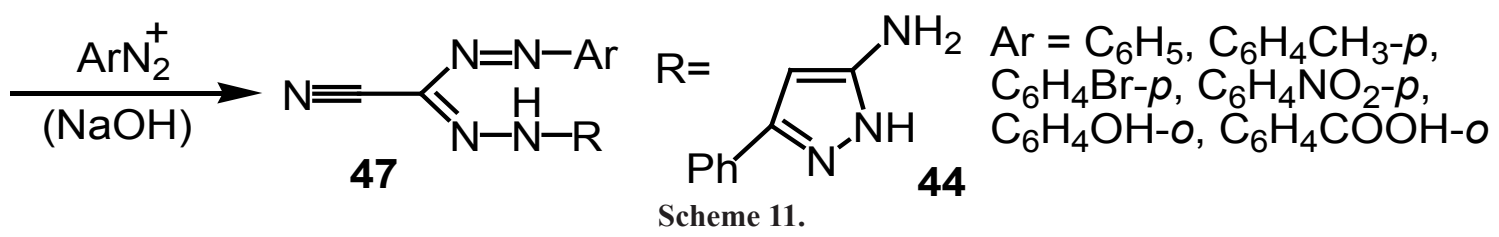

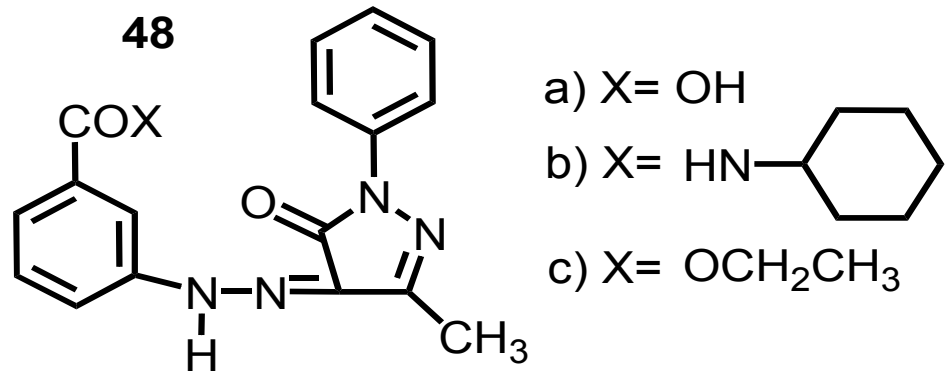

Fig. 6. Chemical structure of the hydrazone dye. 


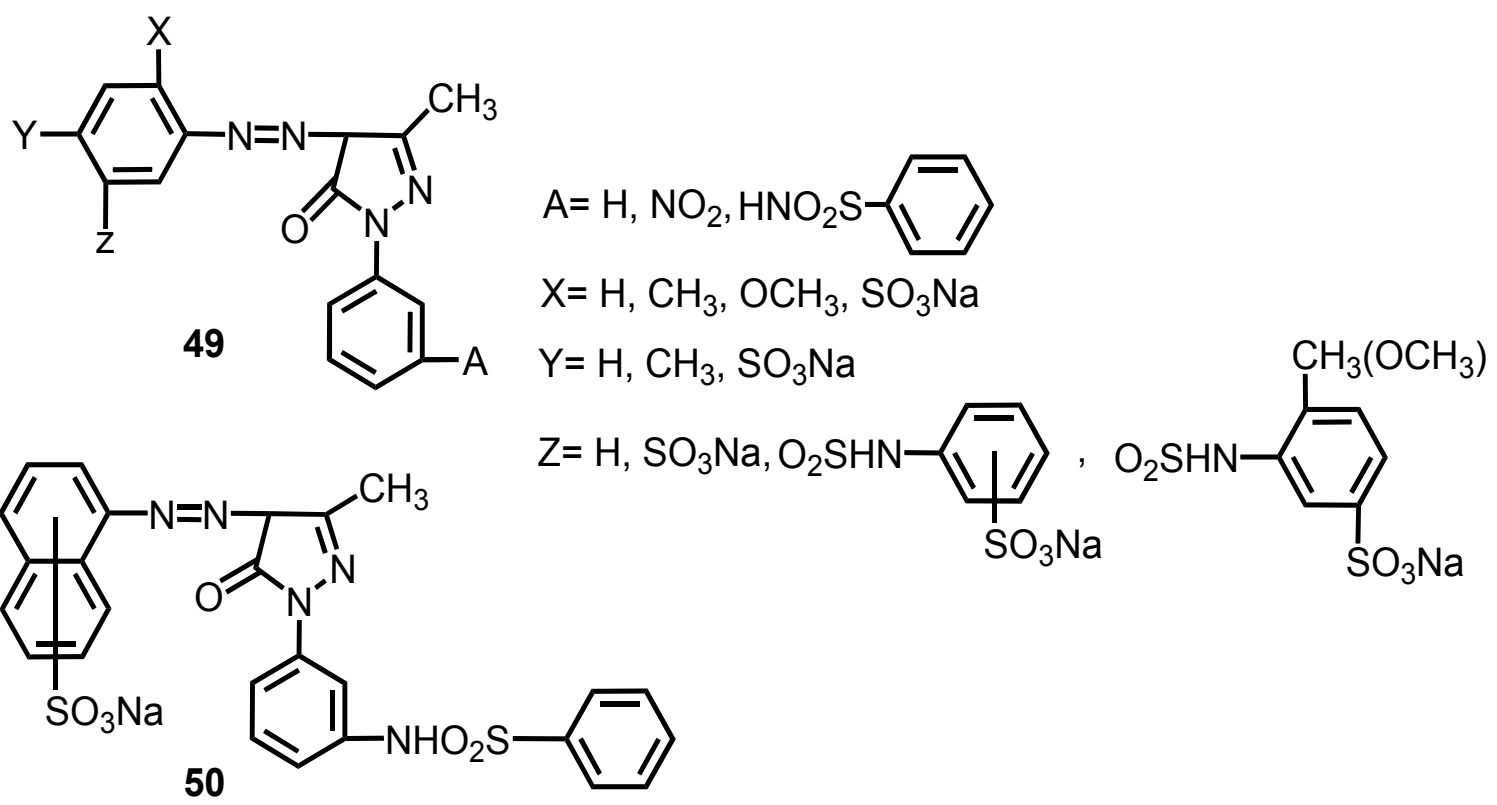

Fig.7. Chemical structure of yellow acid dyes.

Dyes containing arylsulfonamide moiety can be applied on polyamide and wool fibers from weakly acidic dye-bath as the arylsulfonamide functional groups increase their affinity for polyamide giving better leveling, and also enhance the colorfastness to perspiration and wet rubbing. Lower light fastness was observed with derivatives of naphthylaminesulfonic acid and also for derivatives of $o$-anisidine4-sulfonic acid. Dyes derived from toluidine sulfonanilide sulfonic acid show very high light fastness [74].
The copper azo dye complex 51 (Fig. 8) was obtained by condensation of benzene sulfonyl chloride with I-(3'-amino)-phenyl-3-methyl-5pyrazolone in water in acidic medium at $10-15^{\circ} \mathrm{C}$ in the first stage, and $40-45^{\circ} \mathrm{C}$ in the last stage. The azo-coupling process was performed via coupling the diazo components and quinone diazides with I-(3'-N-benzenesulfonamido) phenyl-3-methyl5 -pyrazolone in alkaline medium at $0-5^{\circ} \mathrm{C}$. To produce 1:1 copper-azo dyestuff complex, the alkaline dye solution was reacted with $(\mathrm{Cu}$ $\left.\left(\mathrm{NH}_{3}\right)_{4}\right)^{+2}$ at $35-40^{\circ} \mathrm{C}$ for 34 hours.

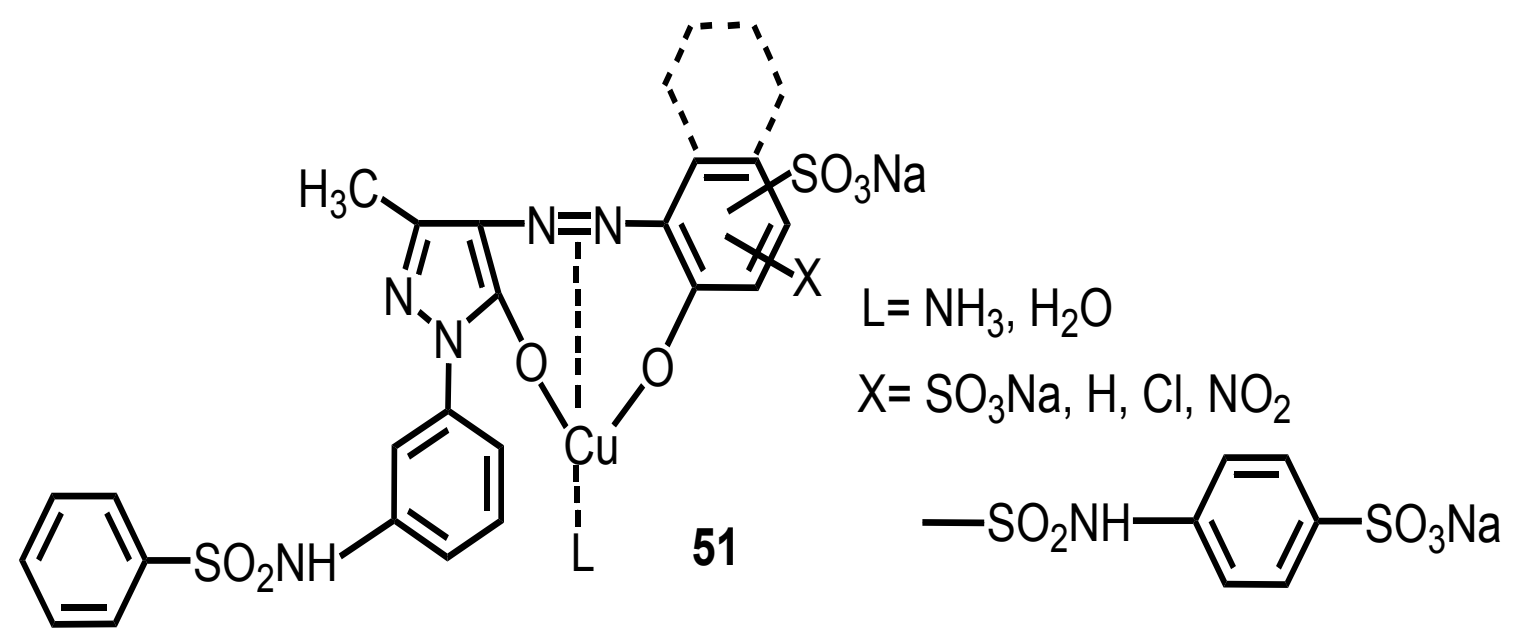

Fig. 8. Chemical structure of the copper azo dye complex. 
Orange and red dyes 51 were very appropriate for dyeing polyamide and wool fibers from a weakly acidic dye-bath solution. The arylsulfonamide group increased their affinity to polyamide and has beneficial influence on the colorfastness to perspiration, light and rubbing [75].

Diazotization of the arylamine 53 and coupling to the imidazole 52 in acidic medium produced the corresponding azoimidazole dyes 54 (Scheme 12).

Compound 52 was synthesized by dehydration of 4(5)-hydroxy-5(4)-imidazole carboxamide [76] which can be prepared via reaction of aminomalonamide and ethyl orthoformate [77]. The $\mathrm{C}^{14}$ labeled analogue has also been synthesized from $\mathrm{C}^{14}$ carbonyl labeled aminomalonamide and ethyl formiminoester [78]. The interaction of 55 with 56 afforded 57 which reacted with nitrous acid to give 58 followed by reduction with sodium dithionite to afford 52 via formation of the intermediate amine 59 (Scheme 13). Dyestuffs were highly liable to degradation under traditional coloration conditions as disperse dyestuffs on synthetic fibers to give dull yellow to brownishyellow shades. Thus, they have no value in this regard [79].<smiles>N#Cc1[nH]cnc1O</smiles><smiles>[X]c1cc([Y])c(N)c([X])c1</smiles><smiles>N#Cc1[nH]c(N=N[Tl])nc1O</smiles>

$\mathrm{X}=\mathrm{H}, \mathrm{OCH}_{3}, \mathrm{Cl}, \mathrm{Br}, \mathrm{CN}, \mathrm{NO}_{2}$

$\mathrm{Y}=\mathrm{H}, \mathrm{OCH}_{3}, \mathrm{NO}_{2}, \mathrm{NHCOCH}_{3}$

$\mathrm{Z}=\mathrm{H}, \mathrm{Cl}, \mathrm{Br}, \mathrm{CN}$

Scheme 12.<smiles>N#CCC(=O)O[CH+]C(N)=O</smiles>

Scheme 13.

Iron complexes of monoazo mordant pyrazole dyes (e.g. Mordant Orange 37 (60) (Fig. 9), Mordant Red 7 and Mordant Brown 15), were produced by treating dyed fibers with iron salts to afford brown to black shades with increased light fastness on wool dyed with afterchrome dyes. In case of other 1:2 iron metalized dyestuffs, [80] the light fastness of iron complexes is less than that of $\mathrm{Cr}$ analogs, but commonly much better than the corresponding metal-free analogs [81]. 


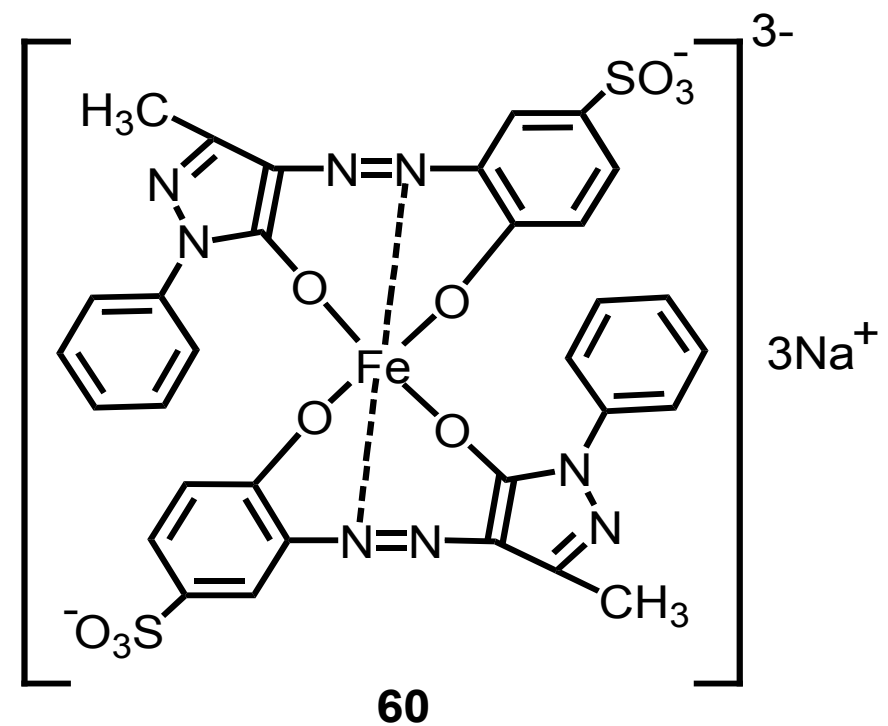

Fig. 9. chemical structure of the Mordant Orange 37.

Compound 61 was reacted with cyanuric chloride followed by diazotization [82] and azocoupling with N-(4'-sulfo)-phenyl-3-methyl-5pyrazolone (SP), to afford 62 which was reacted as basic chromophore with AH to produce 63 [83] (Scheme 14).
Cyanuric chloride was reacted with $\mathrm{AH}$ to produce 64 which was then reacted with 1,3-phenylendiamino-4-sulfonic acid. Without isolation of products 65 , after their diazotization and azo-coupling with (SP), dyes 63a-c were obtained (Scheme 15).<smiles>Nc1ccc(S(=O)(=O)O)c(N)c1</smiles><smiles>Clc1nc(Cl)nc(Cl)n1</smiles><smiles>CCC</smiles><smiles>CNc1nc(Cl)nc(Cl)n1</smiles><smiles>Cc1ccccc1N</smiles><smiles>C=Nc1c(C)nn(C(=C)C)c1O</smiles>

62<smiles>CNc1ccc(S(=O)(=O)O[Na])cc1</smiles>

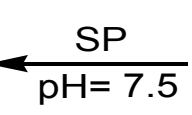<smiles>Nc1cc(Nc2nc(Cl)nc(Cl)n2)ccc1S(=O)(=O)O</smiles><smiles>CCONOONC(C)C</smiles><smiles>O=S(=O)(O)c1ccc(Nc2nc(Cl)nc(Cl)n2)cc1[N+]Cl</smiles><smiles>Cc1nc(Cl)nc(Nc2ccc(S(=O)(=O)O[Na])c(N=Nc3c(C)nn(-c4ccc(S(=O)(=O)OS)cc4)c3O)c2)n1</smiles>

Scheme 14 . 


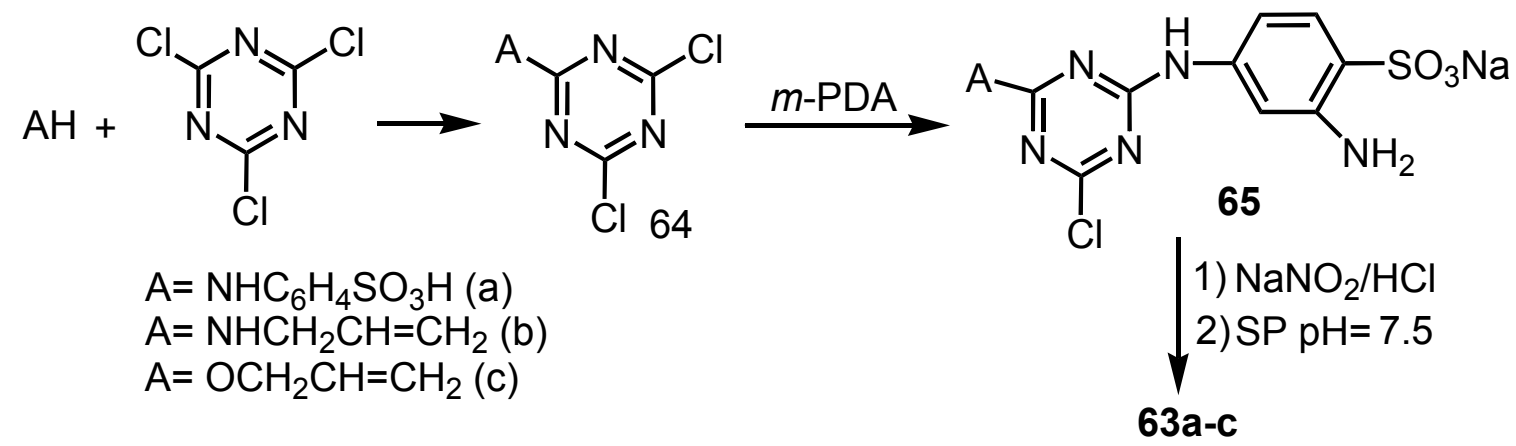

Scheme 15.

A color shift to blue-greenish color was monitored for $63 \mathbf{b} \quad\left(\mathrm{A}=-\mathrm{NHCH}_{2} \mathrm{CH}=\mathrm{CH}_{2}\right)$ and to blue-reddish color for $63 \mathrm{c} \quad(\mathrm{A}=$ $-\mathrm{OCH}_{2} \mathrm{CH}=\mathrm{CH}_{2}$ ) compared to the basic dye 63a $\left(\mathrm{A}=-\mathrm{NHC}_{6} \mathrm{H}_{4} \mathrm{SO}_{3} \mathrm{H}\right)$. Exhaustion of those dyes on cotton fibers was very good and their washing fastness was excellent [84].
Compound 66 (Fig. 10) as potential substitute for benzidine, has been synthesized via interaction among urea and paraphenyldiamine in water. The synthetic approach is simple, cost-effective, and introduced a high quality product.

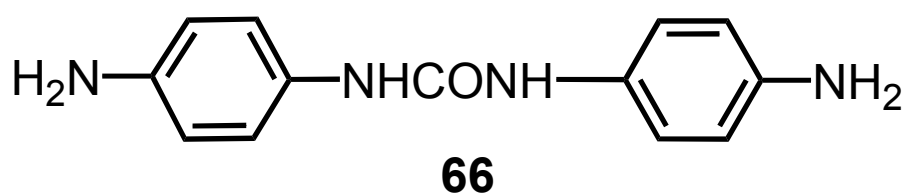

Fig. 10. Chemical structure of the compound 66 .

The direct dye 67 (Fig. 11) can be produced via diazotization followed by azo-coupling with 2,5-dichloro-4-(4,5-dihydro-3-methyl-5-oxo- $1 \mathrm{H}$ pyrazol-1-y1)benzene sulfonic acid and J-acid to afford 67 with fair to good colorfastness properties on cotton fibers. The colorfastness to light was monitored to be the best property [85].

Monoazo dyes 68 (Fig. 12) were employed for dyeing polyester. They were synthesized by diazotization of 4-(2-phenoxyethoxycarbonyl) aniline and coupling with 1-phenyl-3allyloxycarbonyl-5-pyrazolone. They exhibit yellow shade on polyester [86].
Dyes 69 (Fig. 12) were useful for dyeing wool and other protein fibers to afford a strong yellow shade. Those dyes were prepared by coupling the diazonium salt of aminophthalic acid with 1-(4-sulfophenyl-3-methyl-5-pyrazolone) in an aqueous medium containing sodium carbonate [87].

Reactive dyes 70 (Fig. 13) used for dyeing cotton fibers in yellow shades. The reactive dyes 70 were prepared via reaction of cyanuric chloride with $\mathrm{p}-\mathrm{CH}_{3} \mathrm{NHC}_{6} \mathrm{H}_{4} \mathrm{SO}_{2} \mathrm{CH}_{2} \mathrm{OSO}_{3} \mathrm{H}$ and then with 1-(4-aminophenyl)-3-methyl-5-pyrazolone which was coupled with the diazonium salt of 2-aminophthalene-1,5-disulfonic acid [1,2].<smiles>CC1=NN(c2cc(Cl)c(S(C)(=O)=O)cc2Cl)C(=O)C1N=Nc1ccc(NC(=O)Nc2ccc(N=Nc3c([S+](=O)([O-])O[Na])cc4cc(N)ccc4c3O)cc2)cc1</smiles>

Fig. 11. Chemical structure of the direct dye 67. 

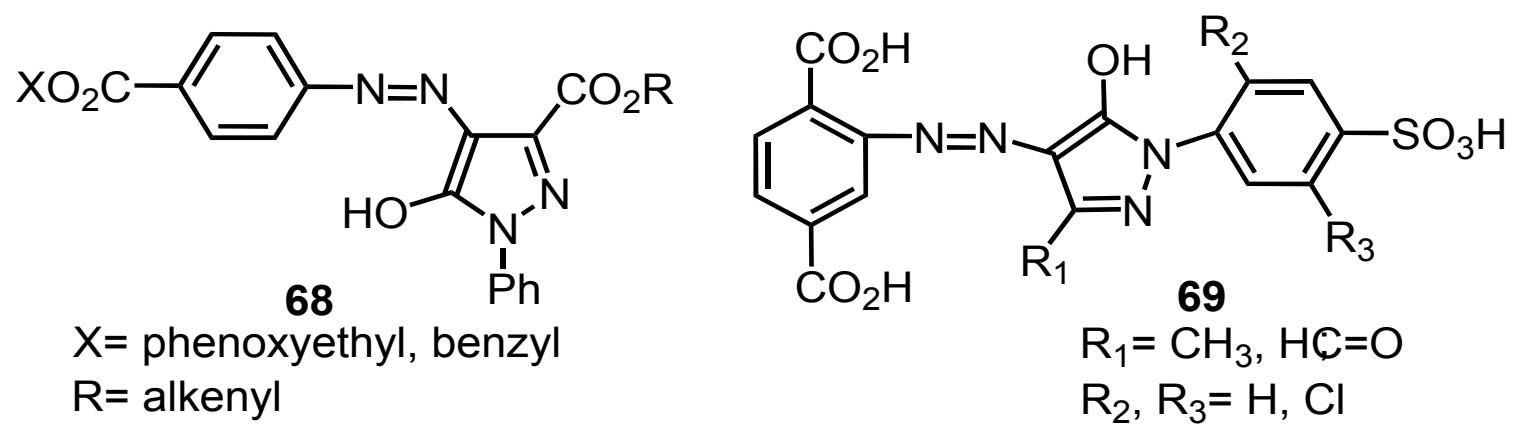

Fig. 12. Chemical structure of monoazo dyes.

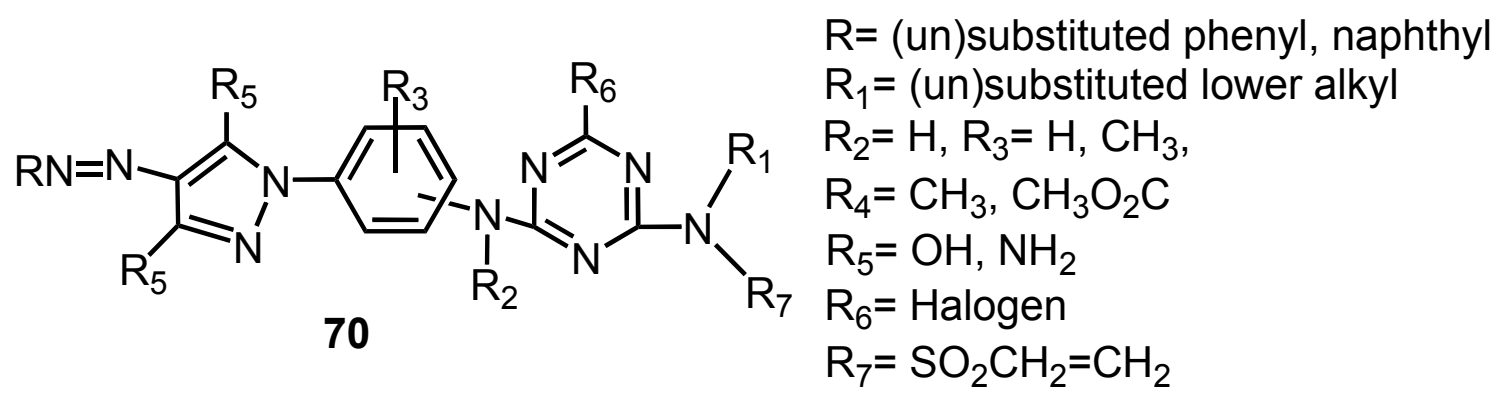

Fig. 13. Chemical structure of Reactive dyes 70.

Dyes 71 (Fig. 14) were prepared by diazotization of p-carbotetrahydr of urfuryloxyaniline and azo-coupling with 1-phenyl-3-carbo-(n-hexyloxyl) pyrazolone. They possess good dyeing power and colorfastness in dyeing hydrophobic fibers in yellow shades, particularly polyester $[1,2]$.
Reactive dyes 72 (Fig. 14) are beneficial for the coloration of hydroxyl and carbonamide group containing fabrics. A sodium salt neutral solution of 4-( $\beta$-sulfatoethylsulfonyl)aniline was subjected to diazotization process and the produced diazonium salt was cyclocondensed and coupled with diethyl acetyl succinate. They have been applied in the coloration of cellulosecontaining fabrics in yellow shades [88].<smiles>[R]OC(=O)c1cc([R2])c(N=Nc2c(C(=O)O[R9])nn(-c3ccccc3)c2O)c([R2])c1</smiles><smiles>[R]OS([R2])([R])N=Nc1c([R])nn(-c2ccc([R4])c([R])c2)c1O</smiles>

$\mathrm{D}=$ benzene ring residue or $\mathrm{C}_{6} \mathrm{H}_{4} \mathrm{NHCOC}_{6} \mathrm{H}_{4}$ $\mathrm{R}=\mathrm{CO}_{2} \mathrm{H} ; \mathrm{R}_{1}, \mathrm{R}_{3}=\mathrm{H}, \mathrm{CH}_{3}, \mathrm{OCH}_{3}, \mathrm{Cl}, \mathrm{Br}$ $\mathrm{R}=$ alkyl, alkenyl $\mathrm{R}_{2}, \mathrm{R}_{4}=\mathrm{H}, \mathrm{CH}_{3}, \mathrm{CH}_{2} \mathrm{CH}_{3}$ $\mathrm{R}_{1}, \mathrm{R}_{2}=\mathrm{H}, \mathrm{Cl}, \mathrm{Br}$ $\mathrm{X}, \mathrm{Y}=$ thiosulphatoethyl, vinyl $\mathrm{R}_{3}=\mathrm{C}_{5-8}$-alkyl, aryl<smiles>[R]OS(=O)(=O)c1cccc(N=Nc2c(C(=O)O[Na])nn(-c3ccc([SH]([O])([O-])=[W])cc3)c2O)c1</smiles>

Fig. 14. Chemical structure of Reactive dyes. 
Water-soluble pyrazolone dyes 73 (Fig. 14) were prepared by coupling the diazonium salt of 3-aminophenylmethylsulfone with 3-carboxy-1(4-sulfophenyl)-5-pyrazolone and hydrolysis in an alkaline environment. They dyed polyamide and wool fibers in yellow to red shades with satisfactory colorfastness to light, washing, rubbing and perspiration [89].

Reactive chloro or fluorotriazines of disazo reactive dyestuffs 74 are practical in combination with disperse dyestuffs on textile fibers containing -OH or -NHCO- group particularly cellulose/ polyester blend affording greenish-yellow shades. Such disazo reactive dyestuffs 74 were synthesized via condensation of cyanuric chloride with 4,4'-diamino-2,2' -stilbenedisulfonic and then with 4-sulfo- $m$-phenylenediamine, diazotization the product and finally coupling with 3-methyl-1[4-(2-sulfatoethyl)sulfonyl]phenyl-5-pyrazolone [90] (Fig.15).
Naphthylazo reactive dye 75 is useful for dyeing fabrics containing hydroxyl or carbonamide group. It was prepared via diazotization of 4-( $\beta$-sulfatoethylsulfonyl) aniline followed by cyclization with acetyl succinic acid diethyl ester at $\mathrm{pH}=4$. The produced pyrazolone intermediate was azo-coupled with 6-( $\beta$-sulfatoethylsulfonyl)1-sulfo-2-naphthylamine diazonium salt to give the reactive dye 75 (Fig. 16) which was employed on cellulosic fiber in a fast yellow shade [91].

A benzotrizole group was incorporated in the chemical structure of the reactive azo dye 76 (Fig. 16) which is useful for dyeing wool, polyamide, or cellulosic fabrics in a fast yellow shade. It was prepared via azo-coupling of 2-amino4-[2-( $\beta$-hydroxyethylsulfonyl) phenylamino] benzenesulfonic acid diazonium salt with 3-methyl-1-( $\beta$ - hydroxyethylsulfonylphenyl)-5pyrazolone [87].<smiles>CCOS(=O)(=O)c1ccc(-n2nc(C)c(N=Nc3cc(Nc4nc(Cl)nc(Nc5ccc(S(=O)(=O)O)cc5)n4)ccc3S(=O)(=O)O)c2O)cc1</smiles>

Fig. 15. Chemical structure of disazo reactive dyes.<smiles>CCOC(=O)c1nn(-c2ccc(S(=O)(=O)OCCCOS(=O)(=O)O)cc2)c(O)c1N=Nc1ccc2cc(S(=O)(=O)O)ccc2c1S(=O)(=O)O</smiles><smiles>Cc1nn(-c2ccc(S(=O)(=O)O)cc2)c(O)c1N=Nc1cc(-n2nnc3ccccc32)ccc1S(=O)(=O)O</smiles>

Fig. 16. Chemical structure of naphthylazo reactive dyes.

Egypt.J.Chem. 61, No.5 (2018) 
Cationic dyes 77 (Fig.17) have been useful for dyeing acrylic, acid-modified polyamide, and acid-modified polyester. The cationic dyestuffs 77 were synthesized by diazotization of 5-amino3-methyl-1-phenylpyrazole and coupling with $\mathrm{N}, \mathrm{N}$-dipropylaniline followed by alkylation with $\left(\mathrm{CH}_{3}\right)_{2} \mathrm{SO}_{4}[92]$.<smiles>[R10]c1ccccc1-n1c(N=Nc2ccc(C([R2])[R2])cc2)cc(C)[n+]1[R17]</smiles>

Dyes 78 (Fig. 18) possess a high color yield and are practical for dyeing textile fibers containing hydroxyl group. Those dyes are synthesized by diazotization of 4-(2-sulfatoethylsulfonyl)-3(2-sulfatoethylsulfonylmethyl) aniline and azocoupling with 1-(4-sulfophenyl)-3-carboxy-5pyrazolone [87].

Fig. 17. Chemical structure of Cationic dyes.<smiles>O=C(O)c1nn(-c2ccc(S(=O)(=O)O)cc2)c(O)c1N=Nc1ccc(S(=O)(=O)O)c(S(=O)(=O)OCCCOS(=O)(=O)O)c1</smiles>

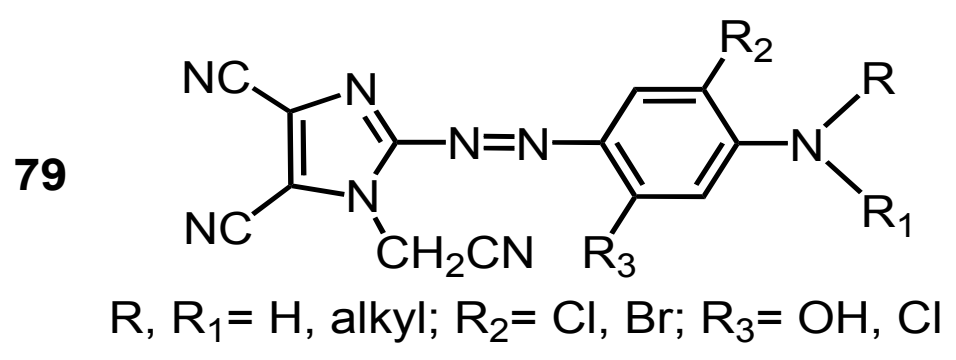

Fig. 18. Chemical structure of Cationic dyes.

Red and bluish-red dyes 79 (Fig. 18) were synthesized via reacting [(4,5-dicyanoimidazole2-yl)azo] anilines with haloacetonitriles or cyanomethyl benzene sulfonates and employed for dyeing polyester fibers [93].

Heterocyclic dyes containing 5-membered ring with three nitrogen heteroatoms

Friedman and Shechter described the direct cyanation of aromatic halides which can be performed easily employing slight excess of cuprous cyanide in dimethylformamide. A mixture of haloaniline and excess of cuprous cyanide was refluxed for 5 hours in dimethylformamide and then treated with ethylene diamine to produce 80 $\left(\mathrm{R}^{1}, \mathrm{R}^{2}=\mathrm{H}, \mathrm{Cl}, \mathrm{CH}_{3}\right)($ Scheme 16).
The triazole 81 was obtained by reaction of $\mathbf{8 0}$ with hydrazine in presence of mercaptoethanol and hydrazine dihydrochloride at $100^{\circ} \mathrm{C}$ for $4-5$ hours.

Only 80 with substituents $\mathrm{R}_{1}=\mathrm{R}_{2}=\mathrm{Cl}$, when subjected to same reaction condition, tetrazine 83 was obtained. Compound $81\left(\mathrm{R}_{1}=\mathrm{R}_{2}=\mathrm{Cl}\right)$ was obtained using large amount of acetic acid and heating for 40 hours. Dihydrotetrazine 82 was formed at first stage and rearranged to 81 under acidic conditions or alternatively air-oxidized, in presence of sodium nitrite, to the corresponding tetrazine 83 (Scheme 17). Tetrazotization of 81 (Scheme 17) was accomplished by adding acetic acid as a co-solvent, and then coupled with acetacetanilide to give yellow pigments 84 .

Egypt.J.Chem. 61, No. 5 (2018) 
<smiles>[X]c1cc([R])c(N)c([R])c1</smiles><smiles>[R]c1cc([N+]#N)cc([R2])c1N</smiles>

Scheme 16.<smiles>[R2]c1cc(-c2nnc(-c3cc([R])c(N)c([R])c3)nn2)cc([R2])c1N</smiles><smiles>[R2]c1cc(C2=NN=C(c3cc([R2])c(I)c([R])c3)NN2)cc([R20])c1N</smiles>
rearrangement

Scheme 17.

The tetra-substituted pigments $84\left(\mathrm{R}_{1}=\mathrm{R}_{2}=\mathrm{Cl}\right.$ and $\mathrm{CH}_{3}$ ) were thermally less stable than others derivatives. The compound $84\left(\mathrm{R}_{1}=\mathrm{R}_{2}=\mathrm{H}\right)$ was thermally stable till $316^{\circ} \mathrm{C}$ and $84\left(\mathrm{R}^{1}=\mathrm{H}\right.$ and $\mathrm{R}^{2}=\mathrm{Cl}$ ) stable at $320^{\circ} \mathrm{C}$ which are considerably superior to Benzidine Yellow 7 (m.p. $200^{\circ} \mathrm{C}$ ) [94] (Scheme 18).

1,2,4-Triazole dyestuffs of the general chemical structure 85 have been applied to hydrophobic fibers. The compounds $85(\mathrm{X}=\mathrm{H})$ and their 5-methylthio analogues $85\left(\mathrm{X}=\mathrm{SCH}_{3}\right)$ (Fig. 19) were found to be inappropriate for polyester fibers in respect to substantivity and colorfastness properties. However, raising the dyestuff hydrophobicity by substitution at the 5-position with (nitro) phenyl group enhanced the dyeing features. The light fastness evaluation was generally poor on polyester, cellulose triacetate and nylon fibers unless a bis-cyano substitution was used which Egypt.J.Chem. 61, No.5 (2018) resulted in ratings of 4 to $4-5$. Compounds $85(\mathrm{X}=\mathrm{A}=\mathrm{H} ; \mathrm{B}=\mathrm{H}, \mathrm{CN})$ were used to afford metal complexes for application on wool and nylon fibers.

$\mathrm{N}$-benzylated-1,2,3-triazolyl derivatives have been claimed as bright red dyestuffs of good colorfastness, and recently, analogous of 1, 2, 4-triazole dyes have been patented [1].

The triazole azo dyes 86 (Fig. 19) were synthesized by benzylation of azo dyestuff which based on $\mathrm{PhEtNCH}_{2} \mathrm{CH}_{2} \mathrm{NPhEt}$ as azocoupling moiety and 3 -aminotriazole as diazo moiety. Those dyestuffs may be employed for bluish-red coloration of acrylic showing rapid and complete dye uptake from the dyebath with good colorfastness. To obtain 87 (Fig. 19), benzylation occurs with benzylp-toluenesulfonate in dimethylformamide containing zinc oxide at $90^{\circ} \mathrm{C}$ [87]. 


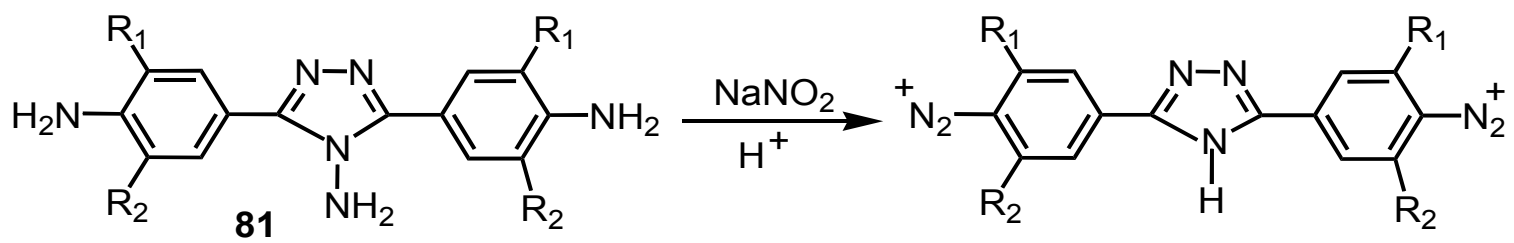

81

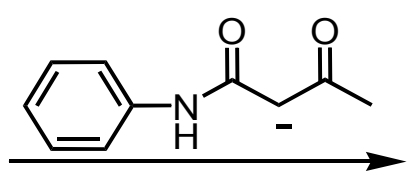<smiles>[R2]c1cc(-c2nnc(-c3cc([R2])c(NC(=O)[C@@H](N=Nc4ccccc4)C(C)=O)c([R2])c3)[nH]2)cc([R2])c1N=NC(C(C)=O)C(=O)Nc1ccccc1</smiles>

Scheme 18<smiles>[R5]CCN(CCC)c1ccc(N=Nc2n[nH]c([X])n2)cc1</smiles><smiles></smiles>

$\mathrm{R}_{1}=\mathrm{H}, \mathrm{CH}_{2} \mathrm{Ph} ; \mathrm{R}_{2}=$ benzyl, $p$-methyl benzyl, $n$-methoxy benzyl; $\mathrm{A}=\mathrm{Cl}$<smiles>[B]c1c(N=Nc2ccc([N+](C)(C)c3ccc(C)cc3)cc2)nnn1C</smiles>

Fig.19. Chemical structure of 1, 2, 4-Triazole dyes.

Dyes 87 were beneficial for dyeing textile substrates and synthesized by azo-coupling 3-amino-1,2,4-triazole diazonium salt with $N$-benzyl- $N$-methylaniline. The product was dispersed in a mixture of water and magnesium oxide and alkylated with $\left(\mathrm{CH}_{3}\right)_{2} \mathrm{SO}_{4}$. Acetic acid was added, the mixture heated and $25 \%$ ammonium hydroxide solution was added to the mixture then stirred and filtered to provide highly concentrated dyestuff solution [95].

Heterocyclic dyes containing 6-membered ring with one nitrogen heteroatom

Pyridine $\mathbf{8 8}$ ( $\mathrm{X}$ is a pyridinium group) (Fig. 20) can be synthsized from pyridinium acetamide. The pyridinium group activates the adjacent methylene group toward pyridone condensation. Compound 89 (Fig. 20) is a very greenish-yellow disperses dye while 90 (Fig. 20) is a greenishyellow cellulose reactive dyestuff. Compound 91 (Fig. 20), a cationic dyestuff for acrylic fibers, was synthesized from pyridinium substituted pyridone. In compound 90 , the pyridone fragment is substituted by sulfomethylene group which introduced by Hegar. Generally, dyestuffs have very good colorfastness and coloration properties and can replace more costly styryl dyestuffs on polyester fibers for very greenish-yellow shades and high tinctorial strength. They are less successful on wool and polyamide fibers due to their low light fastness on these fibers. 
<smiles>[X]c1c(O)cc([Tl])[nH]c1=O</smiles>

88 B<smiles>COc1cccc(N=Nc2c(O)[nH]c(=O)c(C#N)c2C)c1</smiles>

89<smiles>CCn1c(O)c(N=Nc2cc(Nc3nc(Cl)nc(Nc4cccc(S(=O)(=O)O)c4)n3)ccc2S(=O)(=O)O)c(C)c(CS(=O)(=O)O)c1=O</smiles><smiles>[X][C]1C(N=Nc2ccc(N=Nc3ccccc3)cc2)=C(O)NC(=O)[C+]1[n+]1ccccc1</smiles>

Fig. 20. Chemical structure of Pyridine dyes.<smiles>CCN1C(=O)CC(C)=C(C(N)=O)C1=O</smiles><smiles>[2H]N=Nc1c(C)c(C=O)c(C)n(C)c1=O</smiles>

90

$+\quad[\mathrm{NCO}]^{-}$<smiles>NC(=O)Nc1ccccc1</smiles><smiles>Cc1cc(O)[nH]c(=O)c1C#N</smiles><smiles>Cc1cc(Cl)nc(Cl)c1C#N</smiles>

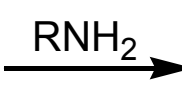

92<smiles>[R]Nc1cc(C)c(C#N)c(N[R])n1</smiles>

Scheme 19. 
Cyanomethylpyridone was reacted with phosphorus oxychloride to form 92 followed by reaction with amines to give 93 (Scheme 19) which was proposed for the synthesis of dyes 9496(Fig. 21). Compounds 94 and 95 are dispersing dyes for polyester fibers with extremely brilliant shades and good light fastness. Dye 95 exhibits an evident hypsochromic nature, since with highly bathochromic 2-cyano-4-nitroaniline diazo, neutral red is produced. Compound 96 is recognized acid dye for polyamide fibers. Compound 98 was prepared using malononitrile dimer as starting material.

Adding hydrobromic acid to nitrile group,

94<smiles>Cc1c(C#N)c(NCCCOCCOc2ccccc2)nc(N)c1N=Nc1ccc([N+](=O)[O-])cc1</smiles>

95

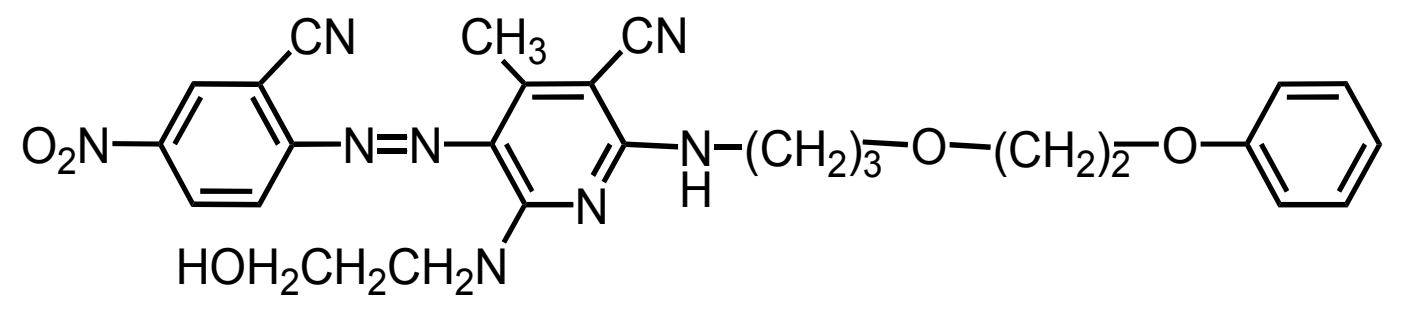<smiles>Cc1c(C#N)c(NCCO)nc(N)c1N=Nc1cc(Cl)c(S(=O)(=O)O)cc1Cl</smiles>

Fig. 21. Chemical structure of dispersing dyes.

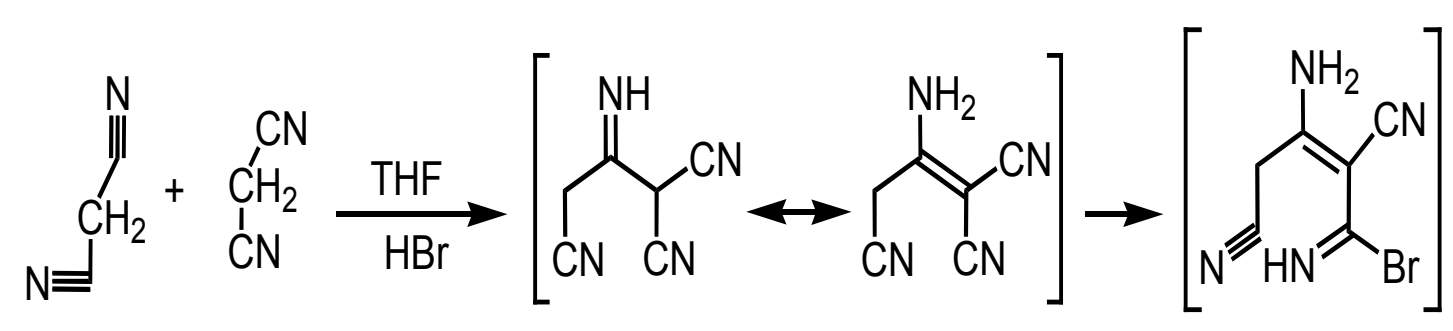

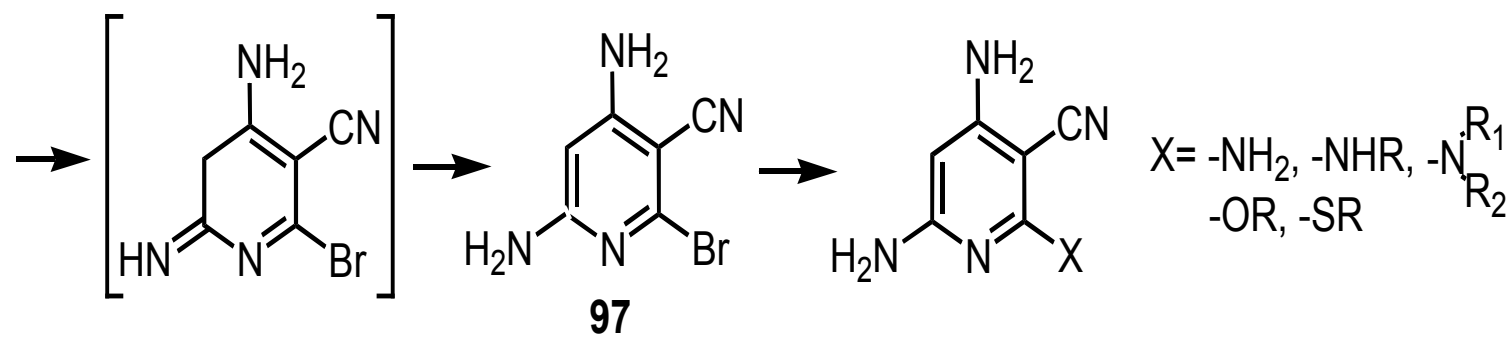

Scheme 20. 
followed by Thorpe-Ziegler ring-closure and formation of isomeric mixture of 97 (Scheme 20). Bromine can be exchanged by nucleophilic reaction with amines, phenols, alcohols or mercapto compounds to afford 98. Red dye 99 was prepared from 98 for polyester revealing very good light fastness and high brilliancy. Triaminocyanopyridine dyes 100 (Scheme 21) were synthesized using malononitrile dimer followed by azo-coupling with diazo material to offer hydrazone which was then reacted with amine, alcohol or mercapto material to result in ring-closure forming cyanopyridine, whereby two isomers may arise. When employing methanol $\left(\mathrm{Y}=-\mathrm{OCH}_{3}\right)$, for example, in ring-closure step, a yellow dyes 101 (Scheme 21) with high standard of colorfastness, was formed [68].

Condensation of isatin with 102 in presence of phosphorus oxychloride in refluxing benzene for 5 hours, yielded disperse dyes 103-105 (Scheme 21) with violet shade. The sublimation fastness of dye 103 was evaluated between 2-3.
In general, dyes 103-105 displayed poor light fastness on polyester substrates [96].

Compound 106 was fused with 107 for 2 hours at $200^{\circ} \mathrm{C}$, to give 108 which was esterified by reflux for 8 hours with ethyl alcohol in presence of $\mathrm{H}_{2} \mathrm{SO}_{4}$ to obtain 109. Both compounds 108 and 109 was coupled with 4-substituted-benzenediazonium chloride $\left(\mathrm{R}=\mathrm{H}, \mathrm{Cl}, \mathrm{CH}_{3}, \mathrm{OCH}_{3}\right)$ to give dyes 110 and 111, respectively (Scheme 22). Mixture of 108 and 112 was heated in phosphoric acid for 2 hours at $170-180^{\circ} \mathrm{C}$, to give 113 which were also obtained by similar reaction between 109 and 112 .

The produced compound 113 was coupled with 4-substituted-benzenediazonium chloride to provide yellow dyes 114. Compound 112 was condensed with p-aminobenzoic acid in polyphosphoric acid, to obtain 115 , which upon fusion with 116 at 210$220^{\circ} \mathrm{C}$ for 4 hours, gave 116 which was coupled with 4-substituted-benzenediazonium chloride to give 117 (Scheme 23).

Compounds 110 and 111 were applied on<smiles>N#Cc1c(N)cc(N)nc1N1CCCCC1</smiles><smiles>N#Cc1c(N2CCCCC2)nc(N)c(N=Nc2ccc([N+](=O)[O-])cc2[N+](=O)[O-])c1N</smiles>

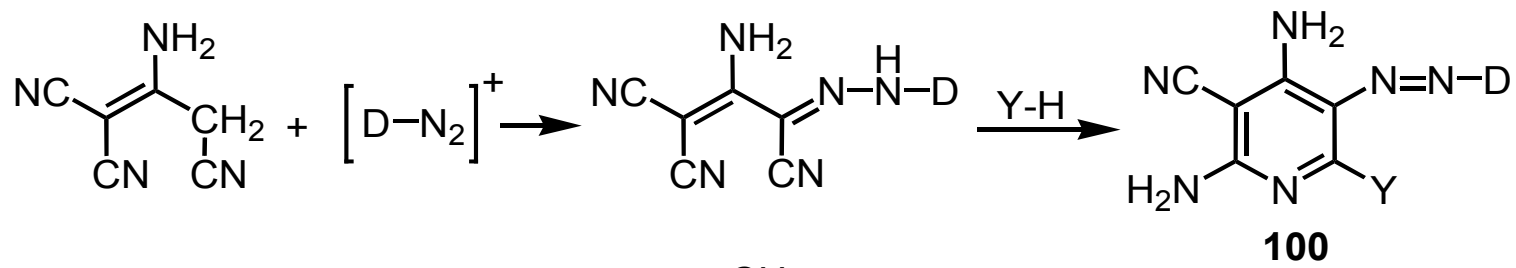<smiles>COc1nc(N)c(/N=N/c2ccccc2)c(N)c1C#N</smiles>

101<smiles>[R]O[GaH]</smiles>

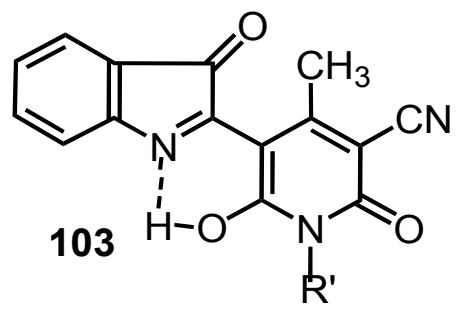<smiles>[R]N1C(=O)C(C#N)=C(C)/C(=C2\C(=O)c3ccccc3N2CC)C1=O</smiles><smiles>[R]c1c(C2=Nc3ccccc3C2=O)c(C)c(C#N)c(=O)n1[Z]</smiles>

Scheme 21. 


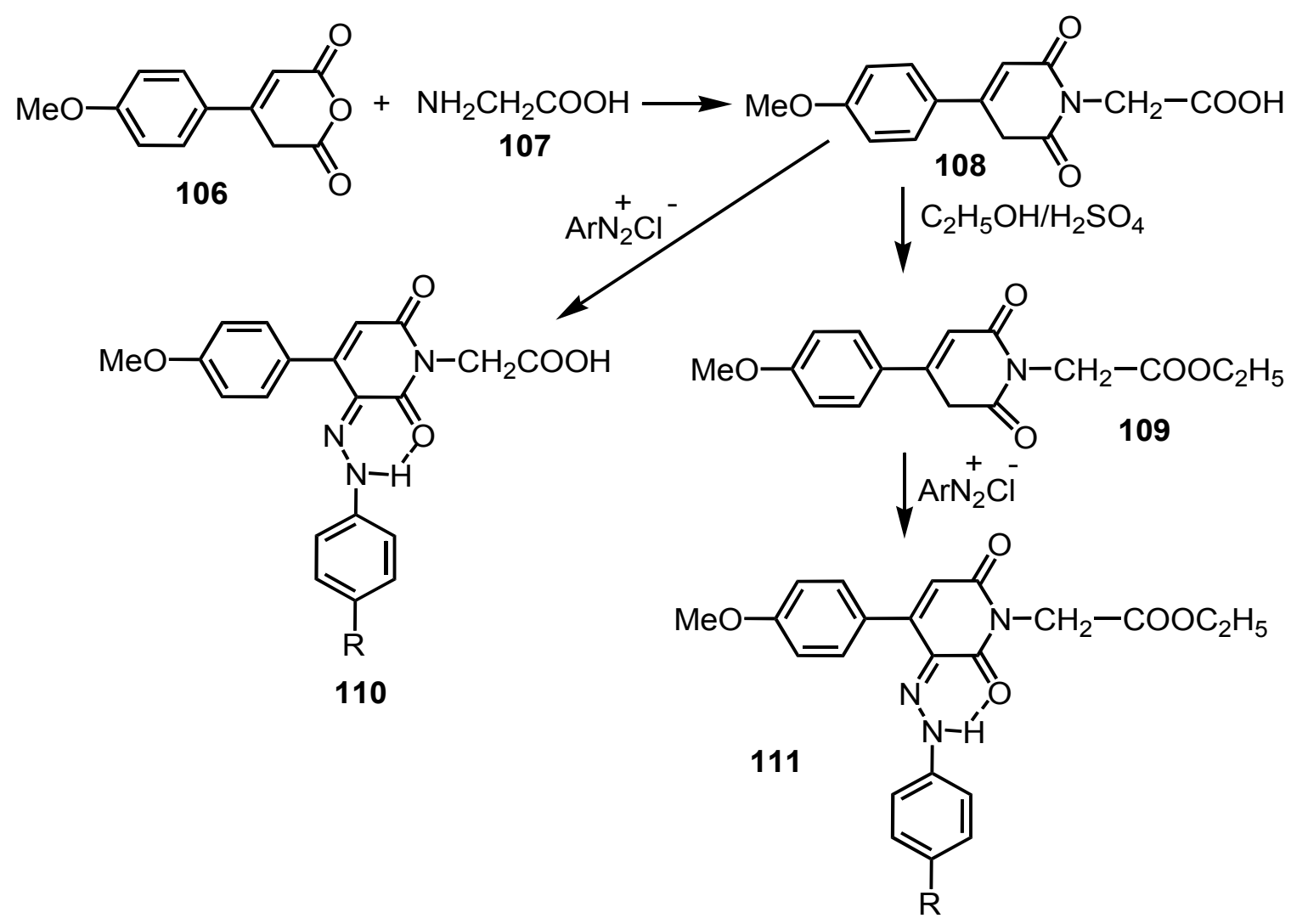

Scheme 22.

polyamide and polyester fibers to afford yellow shades. The carboxylic acid group in 110 made them more suitable than 111 for polyamide fibers, although 111 afforded more intense dyeing on polyester fibers. Dyestuffs 114 and 117 also afforded yellow shades. The existence of a bulky phenyl bridge in 117 among benzimidazole and pyridone rings resulted in much weaker dyeing than the alkylene bridged dyestuffs 114 . Overall light fastness of dyestuffs was good and sublimation fastness of all dyestuffs was excellent. Washing fastness for 111, 114 and 117 (Scheme 23) was better than that of 110 [97] (Scheme 22).

The 2-pyridone compound 120 was prepared from mixture of ethylcyanoacetate 118, ethylacetoacetate 119 , and amine in an ethyl alcohol under reflux and in presence of piperidine as a catalyst. The aniline derivatives 121 were diazotized and their diazonium salts were coupled with the 2-pyridone 120 at $\mathrm{pH}$ 3-4 to give pyridone dyes $122\left(\mathrm{R}=\mathrm{H}, \mathrm{CH}_{3}\right.$, $\mathrm{CH}_{2} \mathrm{CH}_{2} \mathrm{OH}, \mathrm{CH}_{2} \mathrm{CH}_{2} \mathrm{~N}\left(\mathrm{CH}_{3}\right)_{2}, \mathrm{C}_{12} \mathrm{H}_{25} ; \mathrm{X}=\mathrm{H}$,
$\mathrm{CH}_{3}, \mathrm{NO}_{2}$ ) (Scheme 24).

The fabrics dyed with some derivatives of 122 , where $\mathrm{R}=\mathrm{X}=\mathrm{H}$, displayed greener shade and shorter radial chroma than those derivatives, where $\mathrm{X}=\mathrm{NO}_{2}$ or $\mathrm{R}=\mathrm{N}, \mathrm{N}$-dimethylethylene. For dyes, where $\mathrm{X}, \mathrm{R}=\mathrm{CH}_{3}$, shades were yellower and displayed longer radial chroma. They were appropriate for dyeing polyester substrates and gave yellow or greenish-yellow shades [98, 99]. o-Hydroxyanilines were diazotized and coupled at $\mathrm{pH} 3-4$, with pyridones dissolved in sodium carbonate solution, to produce intermediates 123. Purple azo pyridone chromium complexes 124 were prepared by refluxing a mixture of sodium acetate, ammonium chromium(III) sulfate and 123 for 2-3 hours in formamide (Scheme 25).

The azopyridone 123 were applied on polyester to display good washing fastness, but very poor light fastness, while the complex dye 124 displayed excellent washing and light fastness on wool fibers [100]. 

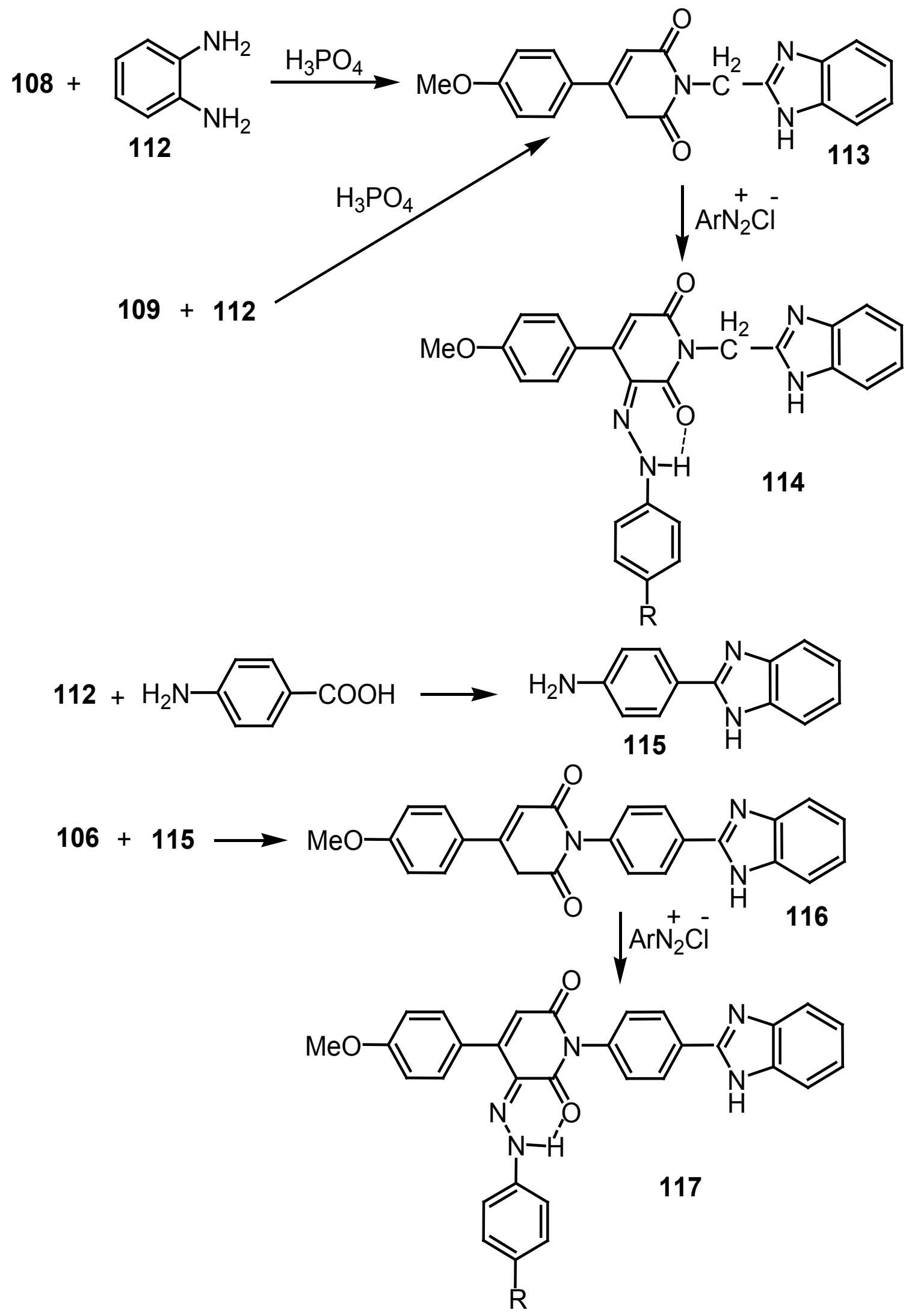

Scheme 23.

Egypt.J.Chem. 61, No.5 (2018) 
$\underset{118}{\mathrm{CNCH}_{2} \mathrm{COOC}_{2} \mathrm{H}_{5}}+\underset{\mathrm{CH}_{3} \mathrm{COCH}_{2} \mathrm{COOC}_{2} \mathrm{H}_{5}}{\mathrm{C}_{119}}+\mathrm{R}_{2} \underset{\text { reflux }}{\text { Ethanol }}$<smiles>[X]c1ccc(N)cc1</smiles>

Scheme 24.

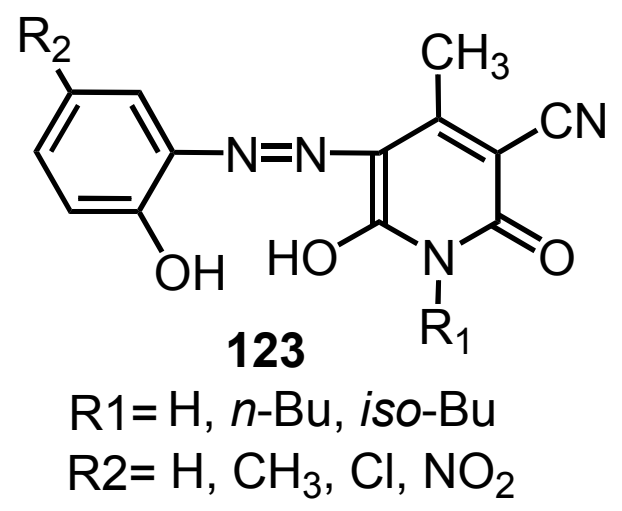

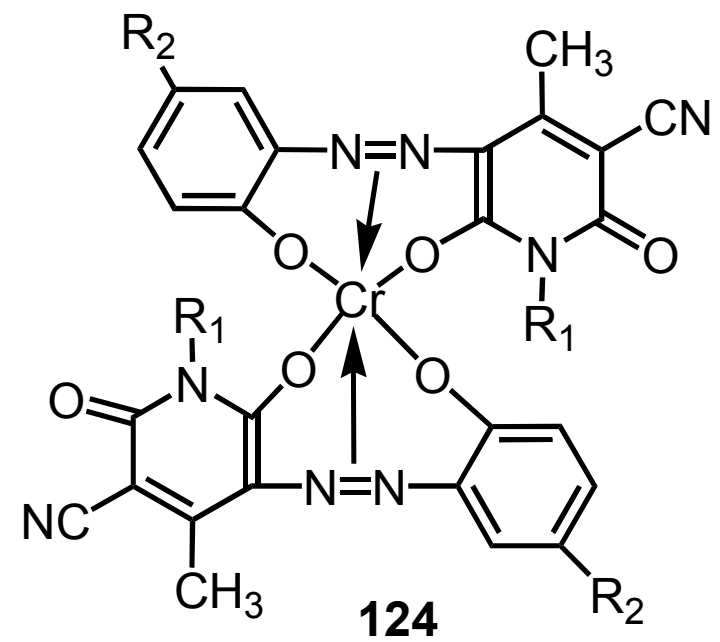

Scheme 25.
The m-nitrobenzene sulfonic acid 125 was converted to its benzenesulfonyl chloride form 126 [101] which was then interacted with substituted phenols at room temperature and under alkaline environment in a biphase system employing tetra-nbutylammonium bromide as a phase transfer catalyst, to afford 127. This was followed by reduction of 127 using tin(II) chloride and concentrated hydrochloric acid afforded 128. Diazotization of 128 followed by azo-coupling with substituted pyridones afforded dyestuffs $129\left(\mathrm{R}_{1}=\mathrm{H}, \mathrm{p}-\mathrm{Cl}, \mathrm{m}-\mathrm{CH}_{3}, \mathrm{o}-\mathrm{CH}_{3} ; \mathrm{R}_{2}=\right.$ $\left.\mathrm{CH}_{3}, \mathrm{C}_{2} \mathrm{H}_{5}, \mathrm{C}_{6} \mathrm{H}_{5}\right)$ (Scheme 26).

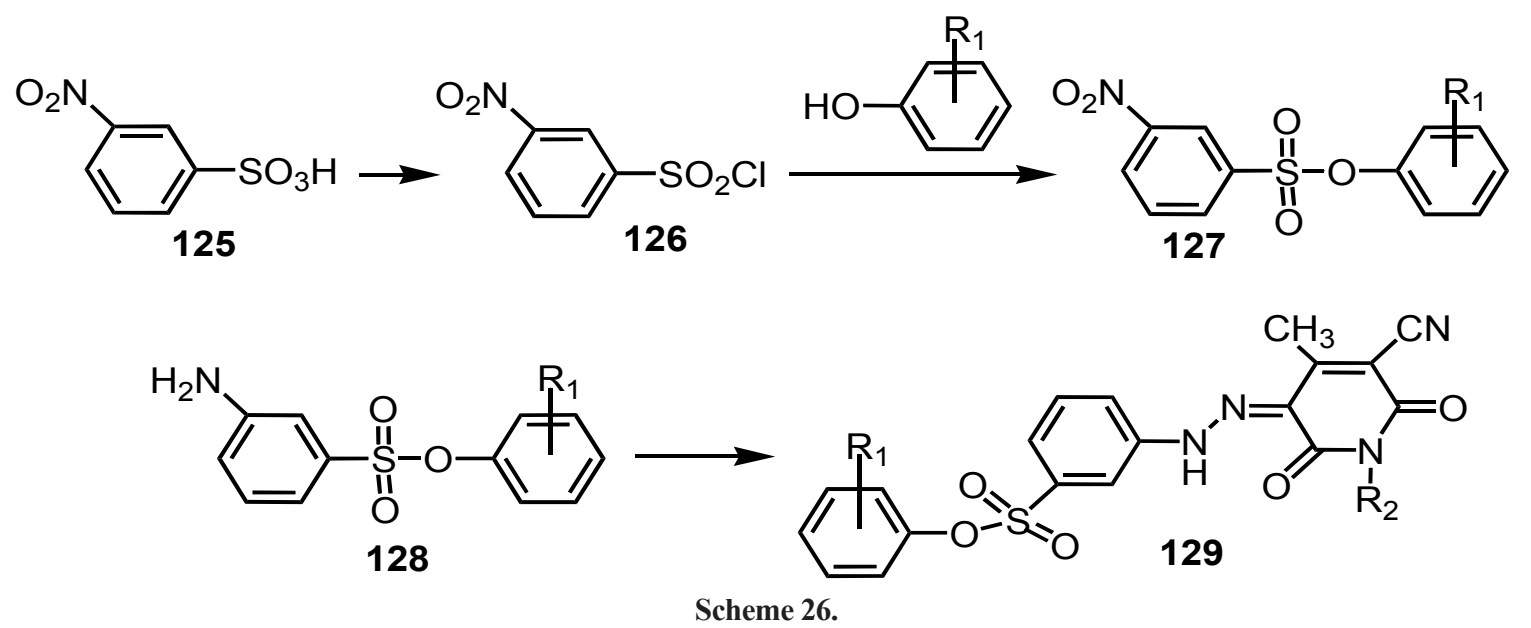


Reaction of m-hydroxyaniline 130 with substituted benzenesulfonyl chloride in presence of tetrabutylammonium chloride as PTC afforded 131. Dyes $132\left(\mathrm{R}_{1}=\mathrm{H}, \mathrm{m}-\mathrm{CH}_{3} ; \mathrm{R}_{2}=\right.$ $\mathrm{CH}_{3}, \mathrm{C}_{2} \mathrm{H}_{5}, \mathrm{C}_{6} \mathrm{H}_{5}$ ) was synthesized from 131 via usual diazotization and azo-coupling reactions (Scheme 27).

The hydrazone compound 129 dyed polyester in bright greenish yellow shades showing excellent deep shades, particularly the derivatives of 129 (where $\mathrm{R}_{1}=\mathrm{H} ; \mathrm{R}_{2}=\mathrm{CH}_{3}, \mathrm{C}_{2} \mathrm{H}_{5}$ or $\mathrm{R}_{1}=\mathrm{o}-\mathrm{CH}_{3} ; \mathrm{R}_{2}=$ $\mathrm{CH}_{3}, \mathrm{C}_{2} \mathrm{H}_{5}$ ). In all cases, dyes 129 offer better shades than that of 132 which include Samaron Yellow 6 GRL $132\left(\mathrm{R}_{1}=\mathrm{H} ; \mathrm{R}_{2}=\mathrm{C}_{2} \mathrm{H}_{5}\right)$, making them highly competitive commercially. Light fastness of majority of dyes was good, particularly $129\left(\mathrm{R}_{1}=\mathrm{H} ; \mathrm{R}_{2}=\mathrm{CH}_{3}, \mathrm{C}_{2} \mathrm{H}_{5}\right.$ or $\mathrm{R}_{1}=\mathrm{o}-\mathrm{CH}_{3} ; \mathrm{R}_{2}=$
$\mathrm{CH}_{3}, \mathrm{C}_{2} \mathrm{H}_{5}$ ). Lighter dyeings were obtained from $\mathrm{N}$-phenylpyridones which displayed moderate light fastness. Sublimation fastness was evaluated between good to very good for all dyes [102].

The azo dyes 133 (Fig. 22) were prepared by diazotization of heterocyclic amine and coupling to the appropriate coupling component [103].

Dyes 133 used as disperse dyes giving good dyeing on hydrophobic fibers such as polyester, polyamide and cellulose acetate fibers. Acceptable exhaustion, color uniformity and color yield were achieved. The colorfastness to solvent, wet treatment and rubbing was preferred on polyester, whereas the light fastness was at its highest on cellulose acetate [104].

PMAN, 1-((pyridin-2-yl)methyleneamino)

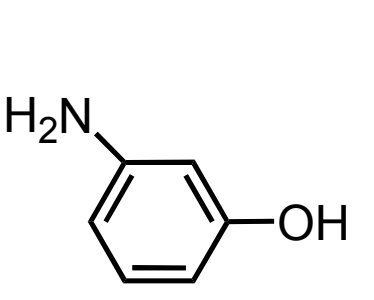

130

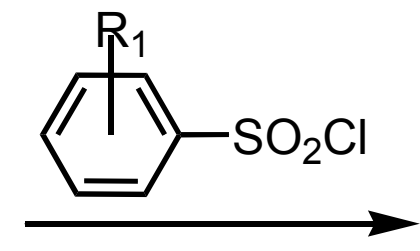

${ }_{-1}^{\mathrm{H}_{2} \mathrm{~N}}$

131<smiles>[R]c1cccc(S(=O)(=O)Oc2cccc(N/N=C3\C(=O)N([R2])C(=O)C(C#N)=C3C)c2)c1</smiles>

Scheme 27.

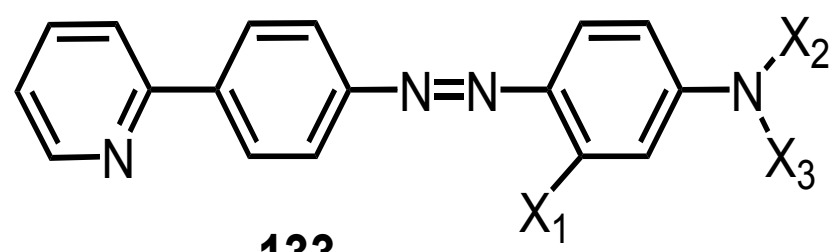

133

$\mathrm{X}_{1}=\mathrm{H}, \mathrm{CH}_{3}, \mathrm{NHCOCH}_{3} ; \mathrm{X}_{2}=\mathrm{CH}_{3}, \mathrm{CH}_{2} \mathrm{CH}_{3}, \mathrm{CH}_{2} \mathrm{CH}_{2} \mathrm{OH}, \mathrm{CH}_{2} \mathrm{CH}_{2} \mathrm{CN}$, $\mathrm{CH}_{2} \mathrm{CH}_{2} \mathrm{OCOCH}_{3} ; \mathrm{X}_{3}=\mathrm{CH}_{3}, \mathrm{CH}_{2} \mathrm{CH}_{3}, \mathrm{H}, \mathrm{CH}_{2} \mathrm{CH}_{2} \mathrm{OH}, \mathrm{CH}_{2} \mathrm{CH}_{2} \mathrm{CN}$, $\mathrm{CH}_{2} \mathrm{CH}_{2} \mathrm{OCOCH}_{3}$

Fig. 22. Chemical structure of the azo dyes 133. 
naphthalen-2-ol, was prepared via reaction of 2-pyridinecarboxaldehyde with 1-amino-2naphthol hydrochloride in ethanol as a solvent and in presence of $\mathrm{CH}_{3} \mathrm{COONa} .3 \mathrm{H}_{2} \mathrm{O}$. The salt $\mathrm{Cu}\left(\mathrm{CH}_{3} \mathrm{COO}\right)_{2} \mathrm{H}_{2} \mathrm{O}$ was dissolved in methanol and mixed with solution of PMAN in ethanol. The produced mixture was refluxed for 30 minutes and a saturated solution of $\mathrm{NaClO}_{4}$ was then added to afford 134. PMAN was dissolved in methanol, and a solution of $\mathrm{Ni}\left(\mathrm{CH}_{3} \mathrm{COO}\right)_{2} 4 \mathrm{H}_{2} \mathrm{O}$ in methanol was then added with stirring. The produced mixture was stirred for 5 hours at ambient temperature and then left to stand overnight, to yield 135 (Scheme 28). PMAN and $\mathrm{Co}\left(\mathrm{CH}_{3} \mathrm{COO}\right)_{2} \cdot 4 \mathrm{H}_{2} \mathrm{O}$ was mixed in methanol followed by stirring for 6 hours at room temperature, and a saturated methanolic solution of $\mathrm{NaClO}_{4}$ was then added, to give 136 (Scheme 28).

A very low dye exhaustion was monitored for Ni (PMAN) $)_{2}$ complex, while a higher exhaustion and better color depth was monitored for Co(PMAN), complex. Highest K/S was obtained for $\mathrm{Cu}-\mathrm{PMAN}$ complex. High washing fastness was obtained, confirming that the substantivity of wool to these metal complex dyestuffs is satisfactory [105].

Dissolving PMAP, 2-(pyridin-2-yl) methyleneamino)phenol, in methanol and adding, with stirring, a solution of $\mathrm{CrCl}_{3} \cdot 6 \mathrm{H}_{2} \mathrm{O}$ in methanol followed by reflux for 2 hours and then allowed to stand overnight at ambient conditions. The dye 137 (Scheme 28) was obtained upon the addition of a saturated solution of $\mathrm{NaClO}_{4}$.

Cr(III)-PMAP complex is a good dyestuff for wool and related fibers showing a higher exhaustion of dye at higher $\mathrm{pH}$ value and introduced a very good washing fastness [106].

Disperse dyes 138 (Fig. 23) were utilized for coloring cellulose acetate and nylon fibers. They can also be applied on silk to afford deep yellow shades.

Both wet and light fastness properties are better than those of acid dyestuffs of same molecular weight, and generally they displayed good colorfastness [107].

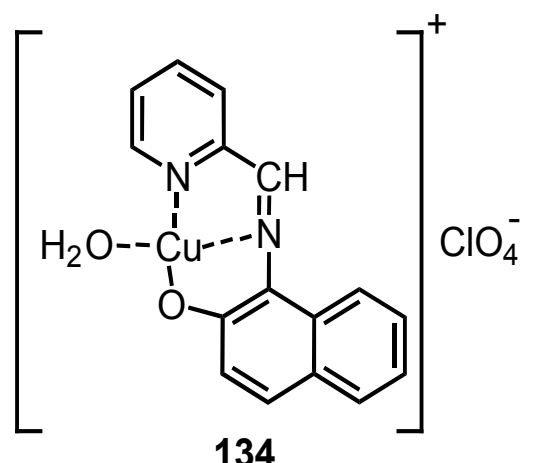<smiles></smiles>

134

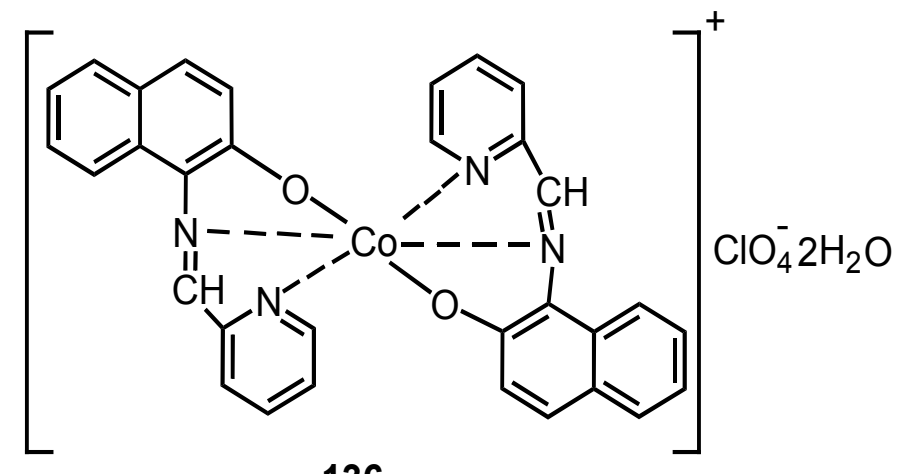

136

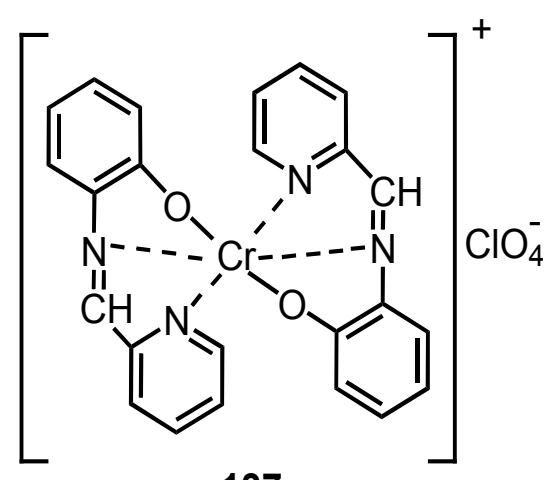

137

Scheme 28. 


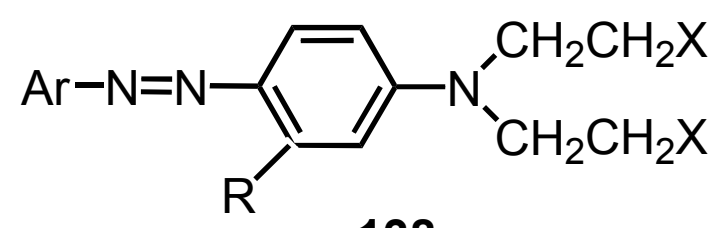

138

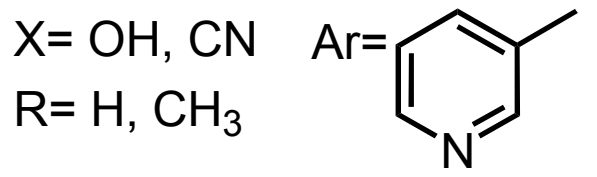

Fig. 23. Chemical structure of the Disperse dyes 138 and the dye complex 139.

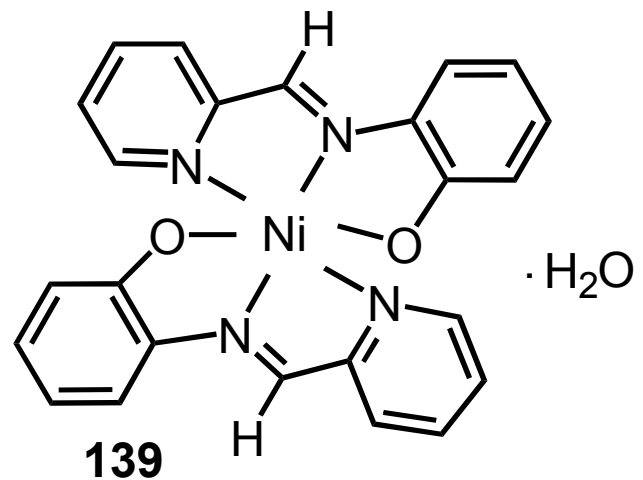

139
PMAP was prepared from 2pyridinecarbaldehyde and 2-hydroxyaniline [108, 109]. The dye complex 139 (Fig. 23) was prepared by addition of PMAP to stirred methanolic solution of $\mathrm{Ni}$ (II) acetate tetrahydrate.

Ni-PMAP was satisfactory dyed polyamide fibers. High washing fastness was monitored for $\mathrm{Ni}-\mathrm{PMAP}$ at $95^{\circ} \mathrm{C}$. Results indicated that $\mathrm{Ni}-$ PMAP is a satisfactory metal complex dye for polyamide and wool fibers [110].

Rieche et al. [111] described introducing an aldehyde group employing dichloromethylalkyl ethers in combination with Friedel-Crafts catalyst and in dichloromethane as a solvent. The interaction of pyrene 140 with dichloro(methoxy)methane 141 in presence of aluminium chloride afforded the precursor 142, which was then hydrolyzed to offer 143. Compound 144 was prepared by condensation of 143 with ethyl cyanoacetate. The cyclization of the pyrene derivative 144 with ketones $(\mathrm{R}=$ pheny, 1, 2-naphthyl, 2-fluorenyl, 2-pyrenyl, 2-pyridyl), produced 145 in presence of excess amount of ammonium acetate (Scheme 29).

The pyrene derivative dye 145 containing 2-pyridyl group (R) in its molecular structure, displayed greener hue and shorter radial chroma than for the dye derivative with phenyl group (R). Dyes with $\mathrm{R}=$ naphthyl, fluorenyl or pyrenyl group at the 6-position of the pyridone ring possess yellow shade, high color purity, and are appropriate as disperse dyestuffs for polyester fibers [112].

Azomethine dye 146 (Scheme 30) was synthesized by mixing $\mathrm{Cu}\left(\mathrm{CH}_{3} \mathrm{COO}\right)_{2} \cdot \mathrm{H}_{2} \mathrm{O}$ and PMAP in methyl alcohol for 6 hours at ambient temperature, and then left to stand overnight followed by the addition of saturated methanolic solution of $\mathrm{NaClO}_{4} \cdot \mathrm{H}_{2} \mathrm{O}$.

Egypt.J.Chem. 61, No.5 (2018)
The complex dye $\mathrm{Cu}-\mathrm{PMAP}$ can be applied on wool at $\mathrm{pH}$ value higher than the fiber isoelectric point because at $\mathrm{pH} 4.5$, the shade became more yellower than at $\mathrm{pH}$ 5.5. Also, the exhaustion was monitored to increase more quickly at $\mathrm{pH} 5.5$ than at $\mathrm{pH} 4.5$. Wool showed very good washing fastness [113].

Pyridone disperse dyestuffs 148 are practical for dyeing synthetic fibers and can be synthesized via azo-coupling of the diazonium salt of 4- $\left(\mathrm{R}_{1} \mathrm{CO}\right)-\mathrm{C}_{6} \mathrm{H}_{4} \mathrm{NH}_{2}$ with hydroxypyridone 147 [2] (Scheme 30).

Different derivatives of disazo dyes 149 were applied on polyester to afford orange shade with excellent build up and alkali fastness. They were prepared via azo-coupling of 4-aminoazobenzene diazonium salt with either 1-ethyl-3-cyano-4methyl-6-hydroxy-2-pyridone or 1-(ethylhexyl)3-cyano-4-methyl-6-hydrxypyridone

[114] (Scheme 30).

Azopyridine dyes 150 were produced from the coupling of 2-chloro-4-nitroaniline diazonium salt with 2-aniline-3-cyano-6- $(\gamma$ methoxypropylamino)-4-methyl-pyridine. Dye 150 dyed polyester with a bluish-red shade showing a light fastness value at 6 [115].

The azopyridone dye 151 is practical at high temperature with excellent colorfastness on polyester affording greenish-yellow shade of superior abrasion resistance. Dye 151 was prepared by coupling the diazonium salt of n-pentyl-4-amino-3-nitrobezoate with 3-cyano1,4-dimethyl-6-hydroxy-2-pyridone

[116] (Scheme 30). 


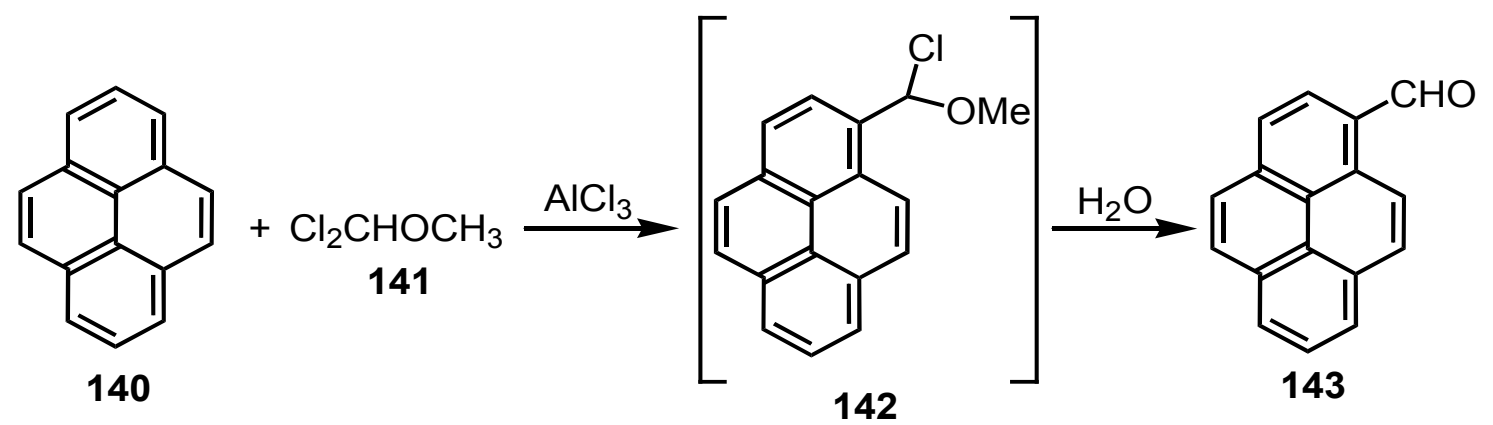

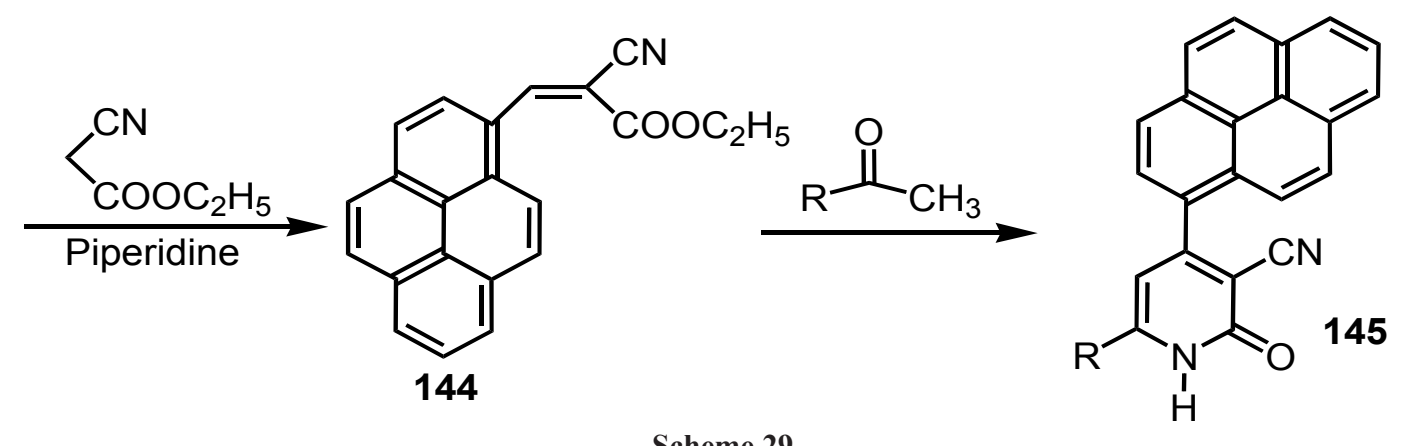

Scheme 29.

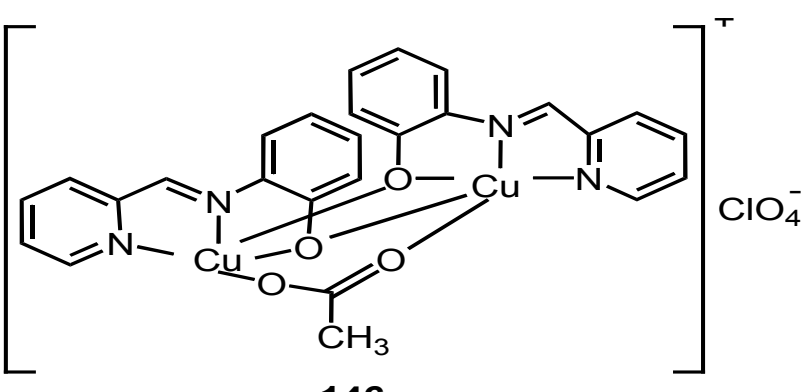

146<smiles>[R4]c1cc(O)n([R3])c(=O)c1[R2]</smiles><smiles>[R17]C(=O)c1ccc(/N=N/c2c([R])c([R4])c(=O)n([R3])c2O)cc1</smiles>

$R_{1}=C_{1-5}$ alkyl; $R_{2}, R_{3}=\left(\right.$ un)substituted $C_{1-12}$ alkyl, $R_{4}=H, C_{1-4}$ alkyl<smiles>Cc1c(N=Nc2ccc(N=Nc3ccccc3)cc2)c(O)n(C)c(=O)c1C#N</smiles>

$\mathrm{R}=\mathrm{CH}_{2} \mathrm{CH}_{3}, \mathrm{R}=\mathrm{CH}_{3}, \mathrm{C}_{3-8}$ alkyl $\mathrm{R}$<smiles>CCOC(=O)c1ccc(N=Nc2c(C)c(C#N)c(=O)n(C)c2O)c([N+](=O)[O-])c1</smiles><smiles>C=CC(=CC)Nc1nc(Nc2ccc([N+](=O)[O-])cc2Cl)c(C#N)c(C)c1N=Nc1ccccc1</smiles>

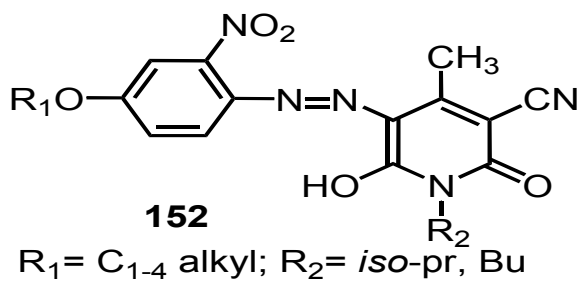

Scheme 30. 
Pyridone azo dyes 152 of different derivatives were obtained by coupling alkoxynitroaniline diazonium salt with different derivatives of 2-pyridone as coupling components. The produced dyes are useful for dyeing polyester substrates in fast shades [117] (Scheme 30).

Pyridyl azo dyes 153 utilized for wool, polyamide and acrylic fibers in a fast red shades, are synthesized by reaction of 2,6-dichloro3-cyano-4-methylpyridine with sulfanilamide at $135-140^{\circ} \mathrm{C}$ to form $N$-(6-chloro-3-cyano4-methyl-2-pyridyl)sulfanilamide which was dissolved in $N$-methyl-2-pyrrolidone and refluxed with 2-hydroxypropylamine. After cooling the reaction mixture, acetic acid was added and the resulting intermediate was coupled with 4-nitroaniline diazonium salt to produce 153 [118].

Dyes 154 (Scheme 31) were synthesized by reacting 2,6-dichloro-3-cyano-4-methyl-pyridine with 4-amino-2,2,6,6-tetraethyl piperidines in dry $\mathrm{CH}_{3} \mathrm{OH}$ with stirring at $40-50^{\circ} \mathrm{C}$. The mixture was then poured into water, the produced precipitate was then condensed with ethanolamine, and finally the product was azo-coupled with the diazonium salt of 2-amino-5-chlorobenzophenone. The colorant 154 dyed acrylic fibers in fast yellow shade $[1,2]$.<smiles>[Y]N=Nc1c(N[R])nc(Nc2ccc(S(N)(=O)=O)cc2)c(C#N)c1C</smiles>

$\mathrm{A}=4$-nitrophenyl, 2-benzoyl-4-chlorophenyl $\mathrm{R}=$ cyclohexyl, 2,2,6,6-tetraethyl piperidyl, 2-hydroxy propyl<smiles>[3H]N=Nc1c(C)c(CC2CC(C)(C)NC(C)(C)C2)nc(NC2CC(C)(C)NC(C)(C)C2)c1C#N</smiles>

$\mathrm{A}=$ aromatic heterocyclic ring<smiles>Cc1c(C#N)c(NCCO)nc(NC2CC(C)(C)NC(C)(Cl)C2)c1N=NN=CCO</smiles>

$\mathrm{A}=\operatorname{aryl}, 2,4-\mathrm{Cl}(\mathrm{Ph}) \mathrm{C}_{6} \mathrm{H}_{3}$<smiles>[R20]OCCN(C)c1c(N=Nc2cc([R])cc([R])c2)c(C)c(C#N)c(=O)n1C</smiles>

$\mathrm{R}=2-\mathrm{CH}_{3} ; \mathrm{R}_{1}=4-\mathrm{NO}_{2} ; \mathrm{R}_{2}=\mathrm{H}$ $\mathrm{R}_{3}=\mathrm{Ph} ; \mathrm{Z}=\mathrm{CH}_{2}, \mathrm{C}_{2} \mathrm{H}_{4}, \mathrm{C}_{2} \mathrm{H}_{4} \mathrm{O} ; \mathrm{n}=2,3$<smiles>Cc1c(C#N)c(NCCO)nc(NC2CC(C)(C)NC(C)(C)C2)c1N=N[Al]</smiles>

$\mathrm{Ar}=$ aromatic heterocyclic ring

Scheme 31. 
Reaction of 2, 6-dichloro-3-cyano4-methylpyridine, 4-amino-2, 2, 6, 6-tetraethylpiperidine and $N$-methyl-2pyrrolidone under heating at $145-155^{\circ} \mathrm{C}$, followed by cooling, and finally azo-coupling with 2 -cyano4-nitroaniline diazonium salt, afforded dyes 155 which dyed acrylic fibers in fast red shade $[1,2]$.

Diazotization of $2,5-\mathrm{Cl}\left(\mathrm{NO}_{2}\right) \mathrm{C}_{6} \mathrm{H}_{3} \mathrm{NH}_{2}$ and azo-coupling with 3-cyano-6-hydroxyl-1- $(\beta$ phenoxyethoxypropyl)-4-methyl-2-pyridone afforded 156 (Scheme 31) which was applied on polyester $[1,2]$.
Diazotization of $2,4-\mathrm{CH}_{3}\left(\mathrm{NO}_{2}\right) \mathrm{C}_{6} \mathrm{H}_{3} \mathrm{NH}_{2}$ and azo-coupling with 3-cyano-6-hydroxy-4-methyl1-[3-(2-phenoxyethoxy)propyl]-2-pyridone afforded pyridinone dyestuff 157 (Scheme 31) which used on polyester [2].

Dyes 158werederivedfrom2,6-diaminopyridine via reaction of 6-chloro-3-cyano-2-[(2hydroxyethyl)amino]-4-methylpyridine with 4-amino-2,2,6,6-tetramethylpiperidine followed by coupling the product with aromatic diazonium salt (Scheme 31). They have been suitable for dyeing acrylic fabrics [2].<smiles></smiles><smiles>O=C(O)c1cc(=O)[nH]c(O)c1N=Nc1cc(Nc2nc(Cl)nc(Nc3ccc(S(=O)(=O)O)cc3)n2)ccc1S(=O)(=O)O</smiles>

$\mathrm{Q}, \mathrm{Q}_{1}=$ halogen, $\mathrm{CN} ; \mathrm{Q}_{2}=$ halogen, $\mathrm{CF}_{3}$

$R_{1}, R_{2}=$ ethylene, propylene; $R_{3}, R_{4}=H$, alkyl $\mathrm{R}_{5}=\mathrm{H}$, halogen; $\mathrm{Z}=$ halogen<smiles>Cc1c(N=Nc2cc(NN3CCN4CCN3CC4Cl)ccc2S(=O)(=O)O)c(O)n(C)c(=O)c1CS(=O)(=O)O</smiles><smiles>[X][M]=Nc1c(C)c(C(N)=O)c(=O)n(CCCCCCCCCCCC)c1O</smiles>

$\mathrm{X}=$ sulfonated aromatic group of fiber-reactive vinyl sulfone or halotriazine type from diazo component.<smiles>[Y7]Nc1nc(Cl)nc(Nc2cc(N=Nc3c(C)cc(=O)n([R])c3O)c(S(=O)(=O)O)cc2[X])n1</smiles>

$\mathrm{R}=\mathrm{H}$, alkyl; $\mathrm{X}=\mathrm{H}, \mathrm{CH}_{3} ; \mathrm{Z}=$ phenylene, naphthalene $\mathrm{Y}=\mathrm{SO}_{2} \mathrm{CH}=\mathrm{CH}_{2} ; \mathrm{R}=$ alkali removable group

Scheme 32.

Trifluorotriazine was reacted with 2-anilino3-cyano-4-methyl-6-[2-(2-hydroxyethoxy) ethylamino]pyridine, then reacted with 3-ethoxypropylamine. The product was coupled with 2, 4-dichloroaniline diazonium salt to afford dye 159 (Scheme 32) which was applied on polyester-cotton blend fabrics [2].

Reactive dyestuff 160 for rayon and cotton fibers was synthesized by reacting 2,4- $\left(\mathrm{NH}_{2}\right)_{2} \mathrm{C}_{6} \mathrm{H}_{3} \mathrm{SO}_{3} \mathrm{H}$ with cyanuric chloride, diazotizing the product, and then azo-coupling with citrazinic acid (Scheme 32). Finally reacting the product with $4-\mathrm{H}_{2} \mathrm{NC}_{6} \mathrm{H}_{4} \mathrm{SO}_{3} \mathrm{H}$ to afford yellow shade on both of cotton and rayon fabrics [2].

Reactive dye 161 (Scheme 32) was prepared via reaction of 5-cyano-2, 4, 6-trichloropyrimidine with 2,4-diaminobenzene sulfonic acid. The product was then diazotized and azo-coupled with 1, 4-dimethyl-6-hydroxy-3-(sulfomethyl)-2pyridone to afford 161 for cotton fibers [119].

Egypt.J.Chem. 61, No. 5 (2018) 
Water soluble reactive pyridine disazo dyes 162 were applied on hydroxyl or carbonamide containing fibers. It was synthesized via cyclocondensation of N, N-bis (cyanoacetyl)1,6-diaminohexane with ethyl acetate to give hexamethylene dipyridine. The product was then coupled with the diazonium salt of the condensation product from cyanuric acid with 4-(2-sulfatoethylsulfonyl) aniline or 1,3-diaminobenzene-4-sulfonic acid [120] (Scheme 32).<smiles>CCCCn1cc(Nc2cccc(O)c2)c(C)c(C#N)c1=O</smiles>

Reactive dye 163 was synthesized and employed for dyeing cotton fibers. Thus, 1,3-phenylenediamine4,6-disulfonic acid was subjected to condensation with cyanuric chloride. The 3-(2-sulfatoethylsulfonyl) aniline was then diazotized and azo-coupled with 1-ethyl-4-methyl-6-hydroxy-2-pyridone to afford dyestuff 163 [121] (Scheme 32).

Reaction of 164 with 2,6-difluoro-4-methyl-5chloropyridine afforded yellow reactive dyestuff 165 used for fibers containing $\mathrm{OH}$ groups such as cotton fibers [122] (Scheme 33).<smiles>[R]c1ccc(N=Nc2c(C)c([R2])c(=O)n([R1])c2O)cc1</smiles>

$\mathrm{R}=\mathrm{H}, \mathrm{NO}_{2} ; \mathrm{R}_{1}=$ alkyl or aralkyl; $\mathrm{Z}=\mathrm{O}$ or $\mathrm{S} ; \mathrm{R}_{2}=\mathrm{CN}$

$\mathrm{R}_{3}=$ active haogen-containing

6-membered $\mathrm{N}$-heterocyclic rings<smiles>[Y][Y]C([R])c1nc(Cl)nc(Nc2cc(N=Nc3c(C)cc(=O)n([R1])c3O)c(S(=O)(=O)O)cc2[X])n1</smiles>

$\mathrm{A}=$ (un)substituted phenylene, naphthalene,<smiles>C=CCn1c(O)c(N=Nc2ccc3ccccc3c2S(=O)(=O)O)c(C)c(CS(=O)(=O)O)c1=O</smiles>

$\mathrm{SO}_{2} \mathrm{CH}_{2} \mathrm{CH}_{2} \mathrm{Z} ; \mathrm{Z}=$ leaving group<smiles>[R]c1c(N=Nc2cc(N)ccc2S(=O)(=O)O)c(O)n([R3])c(=O)c1[R]</smiles>

$\mathrm{R}_{1}=\mathrm{H}, \mathrm{CO}_{2} \mathrm{H} ; \mathrm{R}_{2}=\mathrm{H}, \mathrm{CH}_{3} ; \mathrm{R}_{3}=\mathrm{H}, \mathrm{C}_{1-6}$ alkyl

Scheme 33.

1, 3- $\left(\mathrm{NH}_{2}\right)_{2} \mathrm{C}_{6} \mathrm{H}_{2}\left(\mathrm{SO}_{3} \mathrm{H}\right) 2-4, \quad$ 6-difluoro-5chlorotriazine was neutralized using sodium hydroxide and followed by treating with cyanuric chloride and the resulting product was then condensed with $m-\mathrm{H}_{2} \mathrm{NC}_{6} \mathrm{H}_{4} \mathrm{SO}_{2} \mathrm{CH}_{2} \mathrm{CH}_{2} \mathrm{OSO}_{3} \mathrm{H}$ followed by diazotization and coupling with 1-ethyl-6-hydroxy-4-methyl-2-pyridine to give reactive dyes 166 for dyeing cotton fibers in brilliant fast yellow shades [122].
Bifunctional reactive dyes 167 for dyeing $-\mathrm{OH}$ and -NHCO- containing fabrics were prepared from condensation of 1-(2-aminoethyl)-4-hydroxy4-methyl-3-(sulfomethyl)-2-pyridine with cyanuric chloride. The product was then subjected to condensation with morpholine and nicotinic acid, and the resultant intermediate was azo-coupled with the diazotized 2-amino-6-(2-sulfatoethylsulfonyl)1-naphthalenesulfonic acid (Scheme 33). 
Compound 168 dyed cotton fabrics as reactive dye in strong greenish-yellow shades [123]. Reactive dye 168 was synthesized by diazotization of 4-acetamido-2-aminobenzenesulfonic acid and azo-coupling with 3-carbonoyl-6-hydroxy-1, 4-dimethyl-5-(sulfomethyl)-2-pyridone (Scheme 33). The product was then subjected to deacetylation followed by condensation with 2 , 3-dichloro-6-quinoxalinecarbonylchloride to offer 168 in greenish-yellow shade on cotton fibers [2].

Heterocyclic dyes containing 6-membered ring with two nitrogen heteroatom

Reaction of 169 with substituted amines is the simplest way to produce aminopyrimidine 170. In disperse dye chemistry, the pyrimidine couplers are hypsochromic compared to the dialkylaminobenzene couplers, particularly for the case of red dye 172 which contains a highly bathochromic dinitro-chloroanilinediazo component. Brilliant red dyes 171-173 (Scheme 34) possess a high light fastness and high molar extinction coefficient when used as disperse dyestuffs for polyester fibers or as acid dyestuffs for polyamide fibers.

However, dyestuffs for cellulose fibers from such components are of no significance, due to their unsatisfactory light fastness. The diazo component was coupled with malondialdehyde to result in azo compound, which was then condensed with urea or guanidine derivatives to introduce the final brilliant disperse dyestuff 174 (Scheme 34) of red shade and generally high standard of colorfastness [68].

The acid dyes 175 (Scheme 35) and 180 (Scheme 36) were formed by azo-coupling the sulfanilic acid diazonium salt 178 to $ß$-naphthol and Schaeffer's acid, respectively. Treatment of 175 and 180 with phosphoryl chloride in $\mathrm{N}$, $\mathrm{N}$-dimethylacetamide/acetonitrile/sulfolane afforded 176 (Scheme 35) and 181 (Scheme 36). Condensation of N-methylpiperazine with 176 and 181 in acetone at $35-50^{\circ} \mathrm{C}$ for 2 hours and in presence of $\mathrm{K}_{2} \mathrm{CO}_{3}$ as a base, afforded disperse dyes 177 (Scheme 35) and 182 (Scheme 36) which was then treated with excess of methyl iodide in boiling acetone to give cationic dyes 178 (Scheme 35 ) and 183 (Scheme 36).

The dye 177 did not possess good sublimation fastness, while 182 introduced a very high sublimation fastness. Light fastness of 178 and 183 on acrylic fibers displayed significantly better values than that observed on cationic dyeable polyester, and it is quite good in cases involving 178. Disperse and cationic dyestuffs derived from C.I. Acid Orange 7 and 176 gave much deeper shades, higher exhaustion and higher light fastness than the dyes prepared from intermediate 181 [124] (Scheme 36).

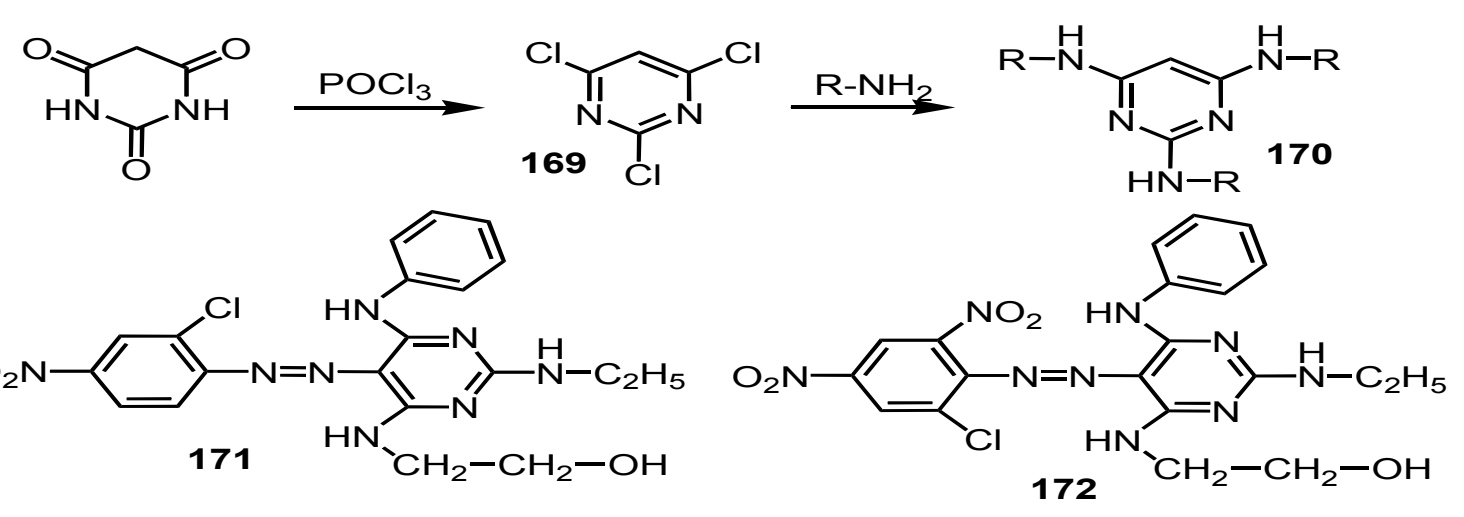

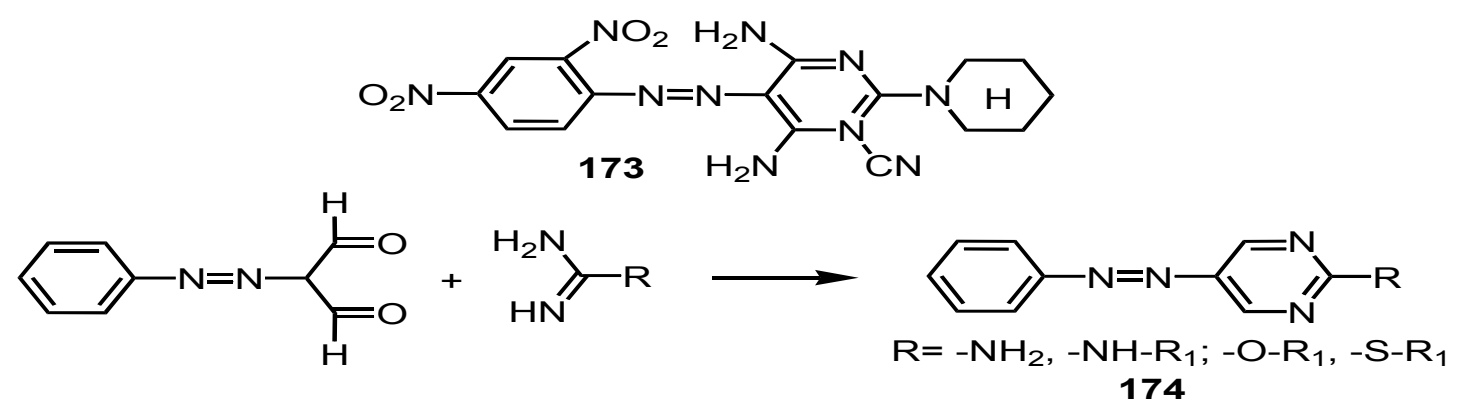

Scheme 34. 


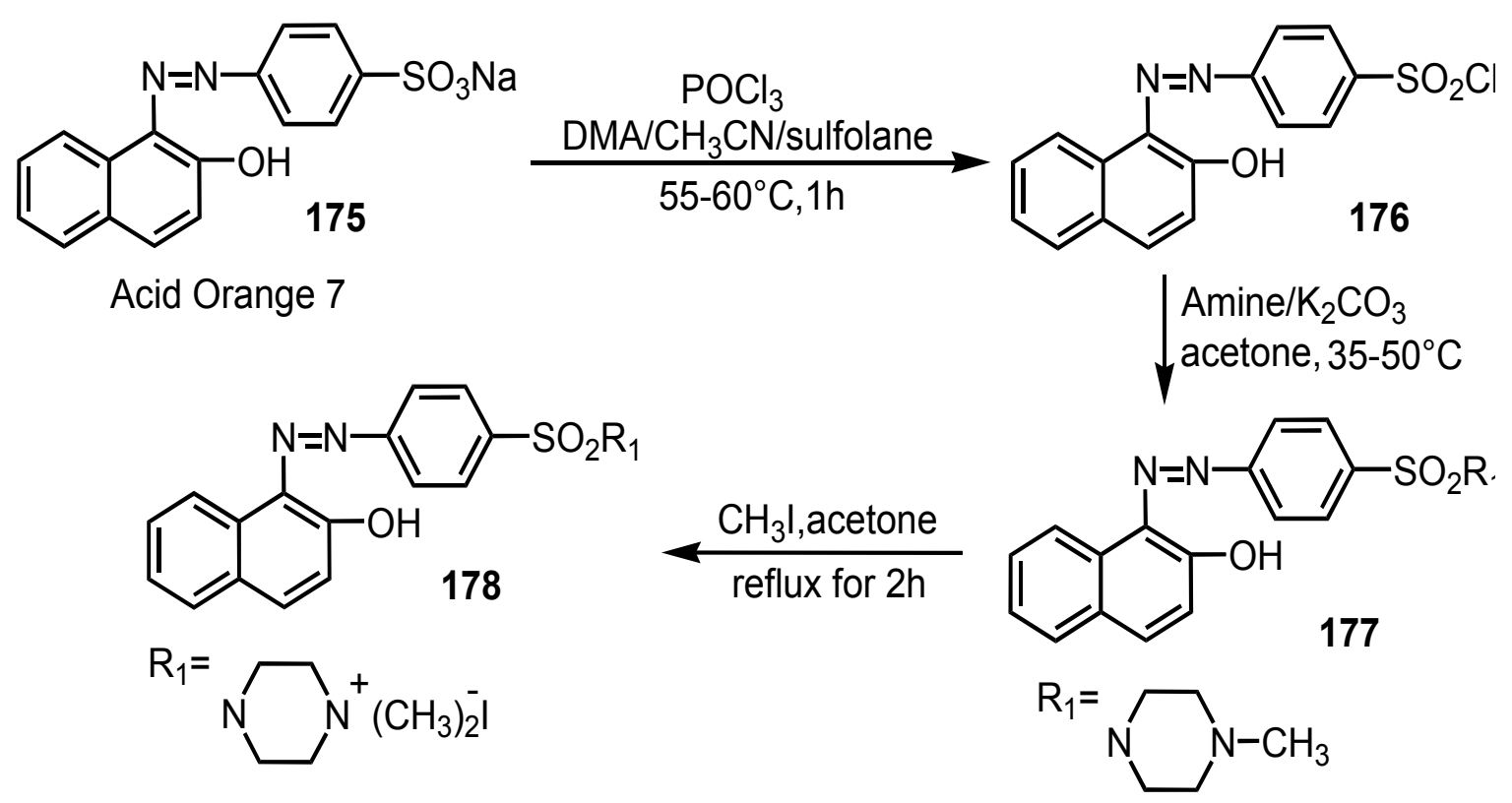

Scheme 35.

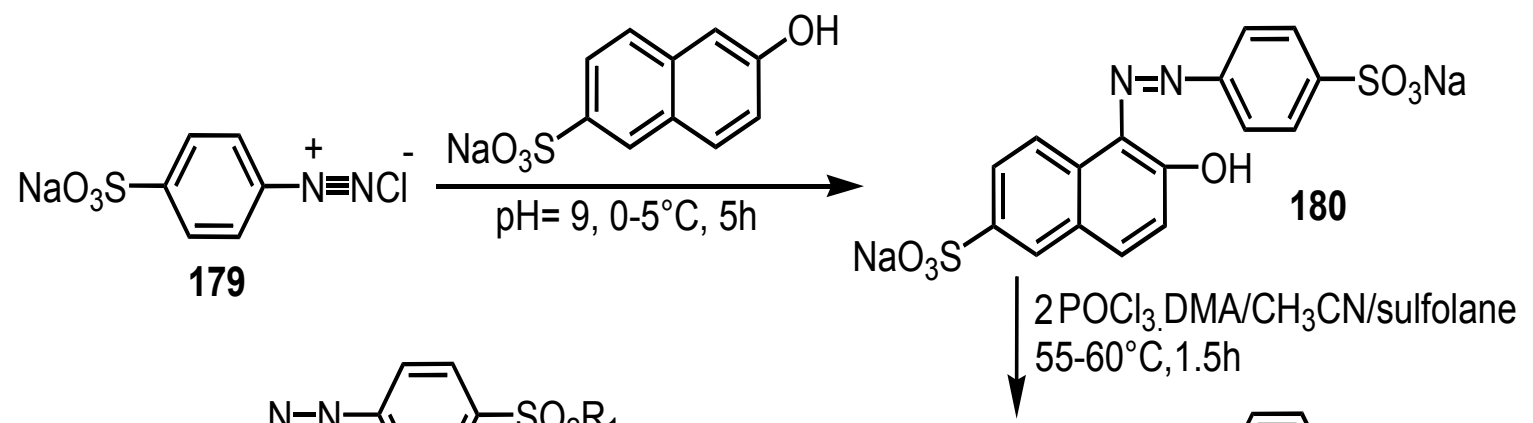<smiles>[R20]Oc1ccc(N=Nc2c(O)ccc3cc(S(=O)O[R20])ccc23)cc1</smiles><smiles>CN1CCNCC1</smiles><smiles>[R7]OS(=O)(=O)c1ccc(N=Nc2c(O)ccc3cc(S(=O)(=O)O[R20])ccc23)cc1</smiles>

Scheme 36 . 


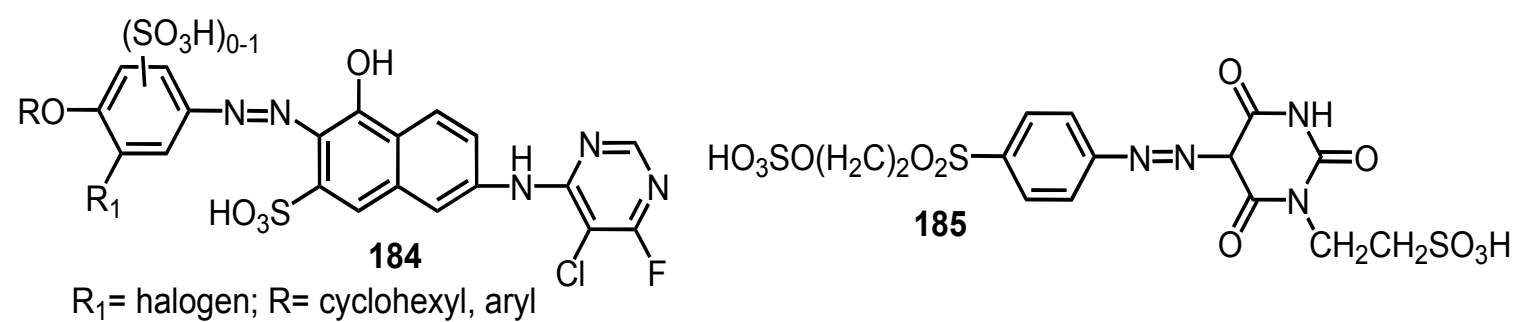

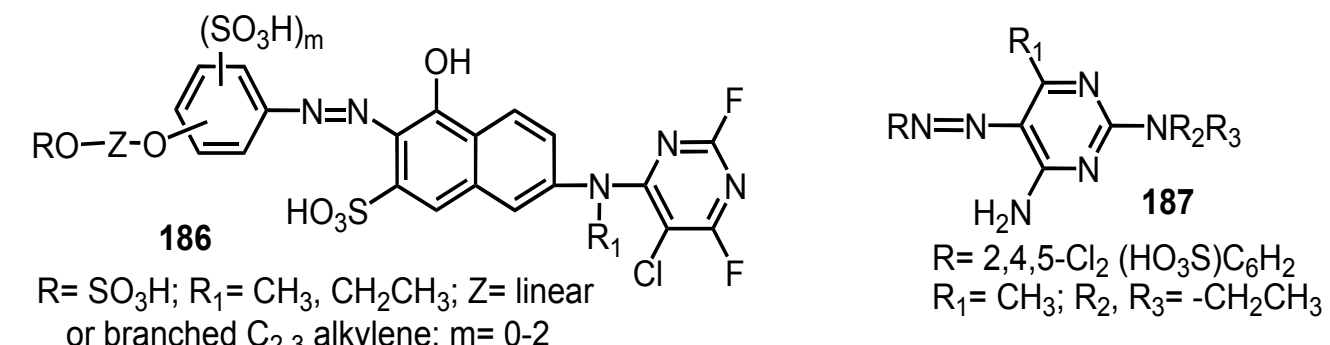<smiles>[X]c1ccc(N=Nc2cc3c4c(c2)CCCN4CCC3)cc1</smiles>

191<smiles>[Y]C1=C(N=Nc2cc([Y4])c([X])cc2[X])C2C=CC=CC12</smiles><smiles>[X]c1ccc(N=Nc2ccc3c(c2)CCCN3[Y])c(C#N)c1</smiles>

192

Fig. 24. Chemical structure of the Reactive dyes and dyes based on 4-aminoazobenzene.

Reactive dyes 184 (Fig. 24) are used for dyeing $-\mathrm{OH}$ and $-\mathrm{NHCO}$ - containing fibers and they were prepared via condensation of 2-amino5-hydroxy-7-naphthalenesulfonic acid with 5-chloro-4, 6-difluoropyrimidine followed by the azo-coupling of the product with 1-amino-4methoxy-2-benzenesulfonic acid [2].

4- $\mathrm{HO}_{3} \mathrm{SCH}_{2} \mathrm{C}_{6} \mathrm{H}_{4} \mathrm{NH}_{2}$ was diazotized and azocoupled with 1-(2-sulfoethyl)barbituric acid to offer greenish-yellow reactive dyestuff 185 for cotton fabrics [125] (Fig. 24).

Compound 186 (Fig. 24) was used for dyeing both natural and synthetic polyamide and rayon fibers. Thus, 4-nitrophenol-3-sulfonic acid was interacted with ethylene chlorohydrin to reduce the nitro group. The produced amine intermediate was then diazotized and azo-coupled with 2-amino-5-hydroxy-7-naphthalenesulfonic acid and the product was subjected to condensation with 5-chloro-2, 4, 6-trifluoropyrimidine to give dyes 186 [126].

The water soluble dye 187 (Fig. 24) was utilized for dyeing polyamide fibers. It was synthesized by diazotization of 2, 4, 5- $\mathrm{Cl}_{2}\left(\mathrm{HO}_{3} \mathrm{~S}\right)$ $\mathrm{C}_{6} \mathrm{H}_{2} \mathrm{NH}_{2}$ and azo-coupling with 4-amino-2(diethylamino)-6-methylpyrimidine [127].

\section{Conclusion}

The preparation and chemistry of nitrogencontaining heterocyclic dyes have been broadly investigated. Many derivatives of this class of materials were verified to be excellent dyestuffs. We introduced a systematic review of recently synthesized 5 and 6 nitrogen-containing heterocyclic dyes and their dyeing efficiency on a variety of textile fibers. 


\section{References}

1. Towns A., Developments in azo disperse dyes derived from heterocyclic diazo components. Dyes and Pigments. 42(1), 3-28. (1999).

2. Hunger K., Industrial dyes: chemistry, properties, applications: John Wiley \& Sons, (2007).

3. Abou-Yousef H., Khattab T.A., Youssef Y.A., Al-Balakocy N., Kamel S., Novel cellulose-based halochromic test strips for naked-eye detection of alkaline vapors and analytes. Talanta; 170, 137-45 (2017).

4. Rather L.J., Akhter S., Hassan Q.P., Mohammad F., Chemistry of plant dyes: Applications and environmental implications of dyeing processes. Current Environmental Engineering; 4(2),103-20 (2017).

5. Khattab T.A., Rehan M., Aly S.A., Hamouda T., Haggag K.M., Klapötke T.M., Fabrication of PAN-TCF-hydrazone nanofibers by solution blowing spinning technique: Naked-eye colorimetric sensor. Journal of Environmental Chemical Engineering; 5(3), 2515-23 (2017).

6. Murphree S.S., Heterocyclic dyes: Preparation, properties, and applications. Progress In Heterocyclic Chemistry: Elsevier; p. 21-58 (2011).

7. Saini A., Christenson C., Khattab T., Wang R., Twieg R., Singer K., Threshold response using modulated continuous wave illumination for multilayer 3D optical data storage. Journal of Applied Physics; 121(4), 043101 (2017).

8. Gregory P., Industrial applications of phthalocyanines. Journal of Porphyrins and Phthalocyanines; 4(4),432-7 (2000).

9. Khattab T.A., Gaffer H.E., Synthesis and application of novel tricyanofuran hydrazone dyes as sensors for detection of microbes. Coloration Technology; 132(6), 460-5 (2016).

10. Luo S., Zhang E., Su Y., Cheng T., Shi C., A review of NIR dyes in cancer targeting and imaging. Biomaterials; 32(29),7127-38 (2011).

11. Khattab T.A., Tiu B.D.B., Adas S., Bunge S.D., Advincula R.C., pH triggered smart organogel from DCDHF-Hydrazone molecular switch. Dyes and Pigments; 130, 327-36 (2016).

12. Zollinger H., Color chemistry: syntheses, properties, and applications of organic dyes and pigments: John Wiley \& Sons, (2003).
13. Abdelmoez S., El Azeem A., Rehab A., Nada A.A, Khattab T.A., Electrospun PDA-CA Nanofibers toward Hydrophobic Coatings. Zeitschrift für anorganische und allgemeine Chemie; 642(3), 219-21 (2016).

14. Centeno S.A., Buisan V.L., Ropret P., Raman study of synthetic organic pigments and dyes in early lithographic inks (1890-1920). Journal of Raman Spectroscopy; 37(10):1111-8 (2006).

15. Nowak M.T., Chen Q., Fluorescent inks for writing instruments using fluorescent dyes and white pigments. Google Patents; (2003).

16. Khattab T.A., Tiu B.D.B., Adas S., Bunge S.D., Advincula R.C., Solvatochromic, thermochromic and $\mathrm{pH}$-sensory DCDHF-hydrazone molecular switch: response to alkaline analytes. RSC Advances; 6(104), 102296-305 (2016).

17. Khattab T.A., Abdelmoez S., Klapötke T.M., Electrospun Nanofibers from a TricyanofuranBased Molecular Switch for Colorimetric Recognition of Ammonia Gas. Chemistry-A European Journal; 22(12), 4157-63 (2016).

18. Khattab T.A., Novel solvatochromic and halochromic sulfahydrazone molecular switch. Journal of Molecular Structure; 1169, 96-102 (2018).

19. Khattab T.A., Rehan M., Hamouda T., Smart textile framework: Photochromic and fluorescent cellulosic fabric printed by strontium aluminate pigment. Carbohydrate polymers; 195, 143-52 (2018).

20. Khattab T., Haggag K.M., Synthesis and spectral properties of symmetrical and asymmetrical 3-cyano-1, 5-diarylformazan dyestuffs for dyeing polyester fabrics. Egyptian Journal of Chemistry; 60, 33-40 (2017).

21. Khattab T.A., Haggag K.M., Elnagdi M.H., Abdelrahman A.A.,AbdelmoezAly S., MicrowaveAssisted Synthesis of Arylazoaminopyrazoles as Disperse Dyes for Textile Printing. Zeitschrift für anorganische und allgemeine Chemie; 642(13), 766-72 (2016).

22. Khattab T.A., Gaffer H.E., Aly S.A., Klapötke T.M., Synthesis, Solvatochromism, Antibacterial Activity and Dyeing Performance of Tricyanofuran-Hydrazone Analogues. Chemistry Select; 1(21), 6805-9 (2016).

23. Vigo T.L., Textile processing and properties:

Egypt.J.Chem. 61, No.5 (2018) 
Preparation, dyeing, finishing and performance: Elsevier, (2013).

24. Gaffer H., Khattab T., Synthesis and characterization of some azo-heterocycles incorporating pyrazolopyridine moiety as disperse dyes. Egyptian Journal of Chemistry; 60, 41-7 (2017).

25. Salabert J., Sebastián R.M., Vallribera A., Anthraquinone dyes for superhydrophobic cotton. Chemical Communications; 51(75), 14251-4 (2015).

26. Atay Ç.K., Kara Y., Gökalp M., Kara I., Tilki T., Karci F., Disazo dyes containing pyrazole and indole moieties: Synthesis, characterization, absorption characteristics, theoretical calculations, structural and electronic properties. Journal of Molecular Liquids; 215, 647-55 (2016).

27. Elapasery M., Shakra S., Abbas D., Gaffer H., Allam E., Synthesis of some azo disperse dyes based on pyridone moiety and their application on polyester fabrics. Egyptian Journal of Chemistry; 60, 97-102 (2017).

28. Elewa S.I., Mohamed M.G., Synthesis and study antimicrobial activities of some novel Tetrazole derivatives. Egyptian Journal of Chemistry; 61(1), 90-100 (2018).

29. Othman H.S., Al-Hashash M., Nawwar G.A.E.M., Cyanoacetyl urea in heterocyclic synthesis part V: Facile synthesis of poly-functionalized pyrimdines via different behaviors of its free urea amino group. Egyptian Journal of Chemistry; 61(1), 20712 (2018).

30. Hafez H.N., Microwave-Assisted Synthesis and Cytotoxicity Evaluation of Some Novel Pyrazole Containing Imidiazoles, Pyrazoles, Oxazoles, Thiadiazoles and Benzochromene Derivatives. Egyptian Journal of Chemistry; 60(6),1015-28 (2017).

31. Mahmoud M., Abdelwahab S.S., Saied K., Synthesis of Novel 2, 3-Disubstituted Quinazolin4- $(3 \mathrm{H})$-ones and Their Antibacterial Activity on the Ultra-structure of Some Pathogenic Microorganisms. Egyptian Journal of Chemistry; 60(6), 1059-66 (2017).

32. El-Sawy E., Abo-Salem H., Mandour A., 1H-Indole-3-carboxaldehyde: Synthesis and Reactions. Egyptian Journal of Chemistry; 60(5), 723-51 (2017).
33. Rizk S., Attia S., Osman D.I., Nessim M., Synthesis and Applications of Pyridazinones for Base Oil Improvement. Egyptian Journal of Chemistry; 60(1),129-(2017).

34. EL-Hashash M., Rizk S., Kadhim M., Facile Synthesis and Structural Characterization of Some Phthalazin-1 (2H)-one Derivatives as Antimicrobial Nucleosides and Reactive Dye. Egyptian Journal of Chemistry; 60(3), 407-20 (2017).

35. Khattab T.A., Synthesis and Self-assembly of Novel s-Tetrazine-based Gelator. Helvetica Chimica Acta; 101(4):e1800009 (2018).

36. Genwa K., Chouhan A., Studies of effect of heterocyclic dyes in photogalvanic cells for solar energy conversion and storage: NaLS-ascorbic acid system. Journal of Chemical Sciences; 116(6), 339-45 (2004).

37. Moreda W., Forrester A.R., Novel heterocyclic dyes as DNA markers. Part I. Synthesis and characterization. Tetrahedron; 53(37), 12595-604 (1997).

38. Pozharskii A.F., Soldatenkov A.T., Katritzky A.R., Heterocycles in life and society: an introduction to heterocyclic chemistry, biochemistry and applications: John Wiley \& Sons, (2011).

39. Fan Z., Song S., Li W., Geng K., Xu Y., Miao Z-H., et al. RhIII-Catalyzed Redox-Neutral C-H Activation of Pyrazolones: An Economical Approach for the Synthesis of N-Substituted Indoles. Organic letters; 17(2), 310-3 (2014).

40. Hallas G., Choi J-H., Synthesis and spectral properties of azo dyes derived from 2-aminothiophenes and 2-aminothiazoles. Dyes and Pigments; 42(3), 249-65 (1999).

41. Ho Y.W., Yao W.H., Synthesis and properties of heterocyclic monoazo dyes derived from 3-cyano-4-trifluoromethyl-6-substituted-2 (1H)pyridinethiones. Dyes and Pigments; 70(1), 60-9 (2006).

42. Nikfar S., Jaberidoost M., Dyes and Colorants. In: Wexler P, editor. Encyclopedia of Toxicology (Third Edition). Oxford: Academic Press; p. 25261 (2014).

43. El-Shishtawy R.M., Ahmed N.S., Anionic coloration of acrylic fibre. Part 1: Efficient pretreatment and dyeing with acid dyes. Coloration Technology;121(3),139-46 (2005).

Egypt.J.Chem. 61, No. 5 (2018) 
44. Wangatia L.M., Tadesse K., Moyo S., Mango bark mordant for dyeing cotton with natural dye: fully eco-friendly natural dyeing. International Journal of Textile Science; 4(2), 36-41 (2015).

45. Schlick B., Artico C., Dyeing a mixed fibre fabric of cellulose/polyacrylonitrile of cellulose/acidmodified polyester with a reactive dye and a basic dye. Google Patents; (1990).

46. Mandal S., Tichit D., Lerner D.A., Marcotte N., Azoic dye hosted in layered double hydroxide: Physicochemical characterization of the intercalated materials. Langmuir; 25(18), 10980-6 (2009).

47. Mori R., Haga T., Takagishi T., Relationship between cellulase treatment and direct dye dyeing for cotton. Journal of Applied Polymer Science; 45(10), 1869-72 (1992).

48. Srikulkit K., Santifuengkul P., Salt-free dyeing of cotton cellulose with a model cationic reactive dye. Coloration Technology; 116(12), 398-402 (2000)

49. Chakraborty J., Jaruhar P., Cotton Dyeing with Sulfur Dyes using Alkaline Enzymes as Alternate Reducing Systems. AATCC Journal of Research; 4(5), 6-13 (2017).

50. Hakeim O.A., Nassar S.H., Raghab A.A., Abdou L.A.W., An approach to the impact of nanoscale vat coloration of cotton on reducing agent account. Carbohydrate Polymers; 92(2),1677-84 (2013).

51. Khatri M., Ahmed F., Shaikh I., Phan D-N., Khan Q., Khatri Z., et al. Dyeing and characterization of regenerated cellulose nanofibers with vat dyes. Carbohydrate Polymers;174, 443-9 (2017).

52. Khattab T.A., Elnagdi M.H., Haggaga K.M., Abdelrahmana A.A., Abdelmoez Aly S., Green Synthesis, Printing Performance, and Antibacterial Activity of Disperse Dyes Incorporating Arylazopyrazolopyrimidines. AATCC Journal of Research; 4(4),1-8 (2017).

53. Sekar N., 2 - Optical effect pigments for technical textile applications. In: Gulrajani ML, editor. Advances in the Dyeing and Finishing of Technical Textiles: Woodhead Publishing; p. 37-46 (2013).

54. Villafana T.E., Delaney J.K., Warren W.S., Fischer M.C., High-resolution, three-dimensional imaging of pigments and support in paper and textiles. Journal of Cultural Heritage; 20, 583-8 (2016)
55. Holme I., 9 - Coloration of technical textiles. In: Horrocks AR, Anand SC, editors. Handbook of Technical Textiles (Second Edition): Woodhead Publishing; p. 231-84 (2016).

56. Balaban I.E., Pyman F.L., CCVI.-The bromoderivatives of 1-methylglyoxaline, and the constitution of "chloroxalmethylin.". Journal of the Chemical Society, Transactions; 125, 1564-72 (1924).

57. Sheppard W., Webster O., Hydrogen cyanide chemistry. V. Diazodicyanoimidazole and dicyanoimidazole halonium ylides. Journal of the American Chemical Society; 95(8), 2695-7 (1973).

58. Sheppard W.A., Begland R.W., Cairncross A., Donald D.S., Hartter D.R., Webster O.W., Hydrogen cyanide chemistry. I. Diiminosuccinonitrile. Journal of the American Chemical Society; 93(19), 4953-5 (1971).

59. James D.S., Disperse mono-and bisazo dyes derived from 2-amino-4, 5-dicyanoimidazole. Google Patents (1978).

60. Sarti-Fantoni P., Donati D., Fiorenza M., Moschi E., Dal Piaz V., The use of 3, 5dimethyl-4-nitroisoxazole for the preparation of $\alpha, \beta$-unsaturated aromatic acids. Journal of Heterocyclic Chemistry; 17(3), 621-2 (1980).

61. Cheng C., Robins R.K., Potential Purine Antagonists. VI. Synthesis of 1-Alkyl-and 1-Aryl4-substituted Pyrazolo [3, 4-d] pyrimidines1, 2. The Journal of Organic Chemistry; 21(11), 124056 (1956).

62. Taylor E. A. McKillop, "The Chemistry of Cyclic Enaminonitriles and o-Aminonitriles,". Advance in Organic Chemistry: Methods and Results; 7 (1970).

63. Schmidt P., Druey J., Heilmittelchemische Untersuchungen in der heterocyclischen Reihe Mitteilung. Pyrazolo-(3, 4-d)-pyrimidine. Helvetica Chimica Acta; 39(3), 986-91 (1956).

64. Dickinson C., Williams J., McKusick B., Aminocyanopyrazoles. The Journal of Organic Chemistry; 29(7), 1915-9 (1964).

65. Weaver M.A, Shuttleworth L., Heterocyclic diazo components. Dyes and Pigments; 3(2-3), 81-121 (1982).

66. Lestina G.J., Regan T.H., Determination of the azohydrazono tautomerism of some 2-pyrazolin-5- 
one dyes by means of nuclear magnetic resonance spectroscopy and $15 \mathrm{~N}$-labeled compounds. The Journal of Organic Chemistry; 34(6), 1685-6 (1969).

67. Baumann H., Dehnert J., Neue synthesen fur diazastyrylfarbstoffel. Chimia; 15(1), 163-\& (1961).

68. Schwander H., Heterocyclic azo coupling components. Dyes and Pigments; 3(2-3), 133-60 (1982).

69. Venturello C., D‘aloisio R., 2-Arylazo-2, 5-dimethyl-3-oxo-2, 3-dihydrofurans, Useful Intermediates in the Synthesis of 1-Aryl-5-methyl3-pyrazolones. Synthesis; 1979(04), 283-7 (1979).

70. Lecher H., Parker R., Conn R., The Reactions of Arylhydrazines with Diketene and the Preparation of 1-Aryl-5-methyl-3-pyrazolones. Journal of the American Chemical Society; 66(11), 1959-63 (1944).

71. Grecu R., Bottaccio G., Parrini V., Monti D., Azoic dyes derived from 1-aryl-5-methyl-3hydroxypyrazoles. Dyes and Pigments; 4(3), 22139 (1983).

72. Galil F.M.A., Khalifa F.A., Abdin T.S., Synthesis and dyeing characteristics of some new asymmetrical 3-cyanoformazans. Dyes and Pigments; 12(1), 49-56 (1990).

73. Gomes J., Griffiths J., Maia H., Moura J., OliveiraCampos A., A novel carboxy-dye reactive system of potential applicability to wool and nylon fibres. Part 1. Studies with model amines. Dyes and Pigments; 17(4), 269-78 (1991).

74. Blus K., Synthesis and properties of acid dyes derived from 1-phenyl-3-methyl-5-pyrazolone. Dyes and Pigments; 20(1), 53-65 (1992).

75. Blus K., Synthesis and properties of 1: 1 copperazo dye complexes derived from 1-Phenyl-3Methyl-5-Pyrazolone. Dyes and Pigments; 25(1), 15-20 (1994).

76. Atsumi T., Tarumi Y., Yoshida N., 2-Substituted 5-hydroxy-1H-imidazole-4-carboxamide derivatives and use. Google Patents (1980).

77. Schipper E., Day A.R., Studies in Imidazoles. II. 1 Imidazo [b] pyrazines2, 3. Journal of the American Chemical Society; 74(2), 350-3 (1952).

78. Miller C.S., Gurin S., Wilson D.W., Substituted Imidazoles as Precursors of the Purines1. Journal of the American Chemical Society; 74(11), 2892-4 (1952).

79. Peters A., Yang S., Chisowa E., Monoazo disperse dyes derived from nitro-2-aminobenzothiazoles. Dyes and Pigments; 28(3), 151-64 (1995).

80. Sokolowska-Gajda J., Freeman H.S., Reife A., Synthetic dyes based on environmental considerations: Part I: iron complexes for protein and polyamide fibers. Textile Research Journal; 64(7), 388-96 (1994).

81. Czajkowski W., Szymczyk M., Iron complexed afterchrome dyes. Dyes and Pigments; 37(3), 197 204 (1998)

82. Waring D.R., Hallas G., The Chemistry and Application of Dyes: Springer Science \& Business Media, (2013).

83. Konstantinova T., Konstantinov H.I., Betcheva R., The synthesis and properties of some unsaturated triazinylstilbene fluorescent brightening agents. Dyes and Pigments; 43(3), 197-201 (1999).

84. Konstantinova T., Petrova P., On the synthesis of some bifunctional reactive triazine dyes. Dyes and Pigments; 52(2), 115-20 (2002).

85. Li Y., Li W., Zhang Y., Liu D., Studies on the synthesis of 4, 4'-diaminodiphenylurea and direct dyes derived therefrom. Dyes and Pigments; 64(1), 35-7 (2005).

86. Niwa T., Himeno K., Yoshihara J., Monoazo dyestuff mixtures to dye polyester yellow. Google Patents (1985).

87. Elgemeie G.H., Helal M.H., El-Sayed H.M., Recent trends in synthesis and application of nitrogen heterocyclic azo dyes. Pigment \& Resin Technology; 30(4), 210-28 (2001).

88. Schlafer L., Schwaiger G., Russ W.H., Watersoluble monoazopyrazolone dyestuffs having fiber reactive groups of the vinylsulfone series. Google Patents; (1990).

89. Stefaniak L., Roberts J.D., Witanowski M., Webb G., A 15N NMR study of some azoles. Magnetic Resonance in Chemistry; 22(4), 215-20 (1984).

90. Schlafer L., Springer H., Kunze M., Process for dyeing hydroxy-containing fiber material with water-soluble dis-azo reactive dye compound. Google Patents; 1989.

91. Tappe H., Oehme D., Schlafer L., Russ W.H., 
Water soluble naphthylazopyrazolone dyestuffs having fiber-reactive groups of the vinylsulfone series. Google Patents (1990).

92. Martins M.A., Pereira C.M., Beck P., Machado P., Moura S., Teixeira M.V., et al. Microwaveassisted synthesis of 5-trichloromethyl substituted 1-phenyl-1H-pyrazoles and 1, 2-dimethylpyrazolium chlorides. Tetrahedron Letters; 44(35), 6669-72 (2003).

93. Imahori S., Himeno K., Maeda S., Mono-azo compound, mono-azo dye and dyeing process for polyester fibers. Google Patents (1982).

94. Matsukawa K., Setsune J., Takagi K., Kitao T. ,Synthesis of 3, 5-bis (m-or m, m'-di-substitutedp-aminophenyl)-n-amino-1, 2, 4-triazole and its application to benzidine yellow type pigment. Dyes and Pigments; 3(4), 307-15 (1982).

95. Hohmann K., Mischke P., Teige W., Novel dye salts of cationic dyes, having thiocyanatometallate or cyanatometallate complex anions for spin dyeing acid modified polyacrylonitrile. Google Patents (1988).

96. Ayyangar N., Lahoti R., Otiv S., Disperse dyes derived by the condensation of homophthalimides and 2-pyridones with naphthostyril and isatin. Dyes and Pigments; 3(4), 317-24 (1982).

97. Dikshit D., Deval S., Deodhar K., Synthesis of benzimidazole substituted pyridone azo disperse dyes. Dyes and Pigments; 6(1), 39-46 (1985).

98. Chen C.C., Wang J., Synthesis of some pyridone azo dyes from 1-substituted 2-hydroxy-6-pyridone derivatives and their colour assessment. Dyes and Pigments; 15(1), 69-82 (1991).

99. Huntsman J.R., A planar-vector based color space for graphic arts color analysis and reproduction. Color Research \& Application; 14(5), 240-59 (1989).

100. Wang J., Hsu Y.J., Tian J.H., Synthesis and properties of some pyridone chromium complex azo dyes. Dyes and Pigments; 16(2), 83-91 (1991).

101. Vogel A., Vogel's Textbook of Practical Organic Chemistry, Revised by B.S. Furniss, A.J.Hannaford, P.W.G. Smith and A.R. Tatchell, ELBS. Longman; (1978).

102. Ayyangar N., Lahoti R., Srinivasan K., Daniel T., Venkataramaih H., Phenyl 3-aminobenzenesulphonates: New intermediates for arylazopyridone disperse dyes. Dyes and Pigments; 17(4), 279-86 (1991).

103. Alberti G., Cerniani A., Seu G., Cationic Dyes for acrylic fibers. 5. cationic dyes derived from several heterocyclic amines with 2 or more heteroatoms. Annali di Chimica; 65(5-6), 305-14 (1975).

104. Viscardi G., Savarino P., Barni E., Quagliotto P., Di Modica G., Botta M., Disperse and cationic azo dyes from heterocyclic intermediates. Dyes and Pigments; 19(1), 69-79 (1992).

105. Koprivanac N., Papic S., Grabaric Z., OstermanParac D., Mesinovic A., Synthesis, characterization and dyeing properties of copper (II), nickel (II) and cobalt (III) complexes of 2-pyridylmethylene1-amino-2-naphthol. Dyes and Pigments; 22(1), 1-13 (1993).

106. Grabarić Z., Koprivanac N., Papić S., ParacOsterman Đ., Matanić H., Synthesis, application and biodegradation of a chromium azomethine dye. Dyes and Pigments; 23(4), 255-65 (1993).

107. Seu G.,The dyeing of silk with heterocyclic disperse azo-dyes. Dyes and Pigments; 23(4), 26773 (1993).

108. Grabarić Z., Eškinja I., Koprivanac N., Mešinović A., Characterization of $\mathrm{Ni}$ (II) and $\mathrm{Cu}$ (II) complexes of 4-(2-Quinolylmethyleneamino)1-phenyl-2, 3-dimethyl-5-pyrazolone and their analytical applications. Microchemical Journal; 46(3), 360-6 (1992).

109. Geary W., Nickless G., Polland F., The metal complexes of some azo and azomethine dyestuffs: Part I. Spectra in water, and in dioxan/water in the wavelength range 320-600 $\mathrm{m} \mu$. Analytica Chimica Acta; 26, 575-82 (1962).

110. Papić S., Koprivanac N., Grabarić Z., ParacOsterman Đ., Metal complex dyes of nickel with schiff bases. Dyes and Pigments; 25(3), 229-40 (1994).

111. Rieche A., Gross H., Höft E., Über $\alpha$-Halogenäther, IV. Synthesen aromatischer Aldehyde mit Dichlormethyl-alkyläthern. European Journal of Inorganic Chemistry; 93(1), 88-94 (1960).

112. Chen J.J., Wang J.. Synthesis and colour assessment of some 3-cyano-4-pyrenyl-6substituted-2-pyridone derivatives. Dyes and Pigments; 29(4), 305-13 (1995). 
113. Koprivanac N., Papić S., Hergold-Brundić A., Nagl A., Parac-Osterman Đ., Grabarić Z., Constitution and dyeing properties of a 2: 2 copper complex azomethine dye. Dyes and Pigments; 35(1), 57-68 (1997).

114. Imahori S., Himeno K., Yoshihara J., Phenyl acothienylthiazoaniline dis-azo dye for polyester fibers. Google Patents (1989).

115. Himeno K., Sekioka R., Monoazo dye having diaminopyridine derivatives. Google Patents; (1994).

116. Himeno K., Yoshihara J., Ishida M., Red benzothiazole monoazo dye for polyester fiber, mixed dye containing the same, and method of dyeing polyester fiber using the same. Google Patents (1988).

117. Urgen Schaetzer J., Azothiophene dyes containing a 2, 4, 6-triamino-3-cyanopyridine coupling component. Google Patents (1997).

118. Naik D., Desai K., Heterocyclic monoazo dyes derived from 4-oxoquinazoline. Dyes and Pigments; 14(1), 1-7 (1990).

119. Auerbach G., Brenneisen K., Doerr M., Doswald P., Gisler M., Koch W., et al. Dyes having one or two 2, 4-or 4, 6-dichloro-5-cyanopyrimidyl groups linked through bridging radicals containing at least two nitrogen atoms to chloro-1, 3, 5-triazinyl groups. Google Patents (1993).

120. Reiher U., Russ W.H., 2-amino-8-hydroxy-6sulfonaphtalene-containing monoazo reactive dyes. Google Patents (1996).
121. Kayane Y., Miyamoto T., Omura T., Sawamoto H., Harada N., Takeshita A., 4-methylpyridone monoazo compound having both monochlorotriazinyl and vinylsulfone type fiberreactive groups. Google Patents (1986).

122. Niwa T., Himeno K., Hihara T., Shimizu Y.. Reactive monoazo and disazo pyridone dyestuffs containing a halo-substituted 6-member nitrogencontaining heterocyclic ring. Google Patents (1986).

123. Michna M., Hoppe M., Herd K-J., Henk H., Stohr F-M., Reactive dyestuff preparations containing pyridine derivatives. Google Patents (1993).

124. Sokolowska-Gajda J., Freeman H.S., The synthesis of disperse and cationic dyes from acid dye structures. Dyes and Pigments; 14(1), 35-48 (1990).

125. Ehrenberg S., Engel A., Henk H., Reactive dyestuffs based on a substituted barbituric acid. Google Patents (1996).

126. Auerbach G., Moser H.A., Monoazo compounds having a 6-(5'-chloro-2', 4'-difluoropyrimid-6'ylamino)-1-hydroxy-3-sulfonaphthalene group and their use as dyes. Google Patents (1989).

127. Hahn W., Muszynski M., Disperse dyes derived from 3-arylazo-5-cyano-4-methyl-1H-pyrazolo [3, 4-b] pyridine. Chem Stosow; 30(3), 421-9 (1986).

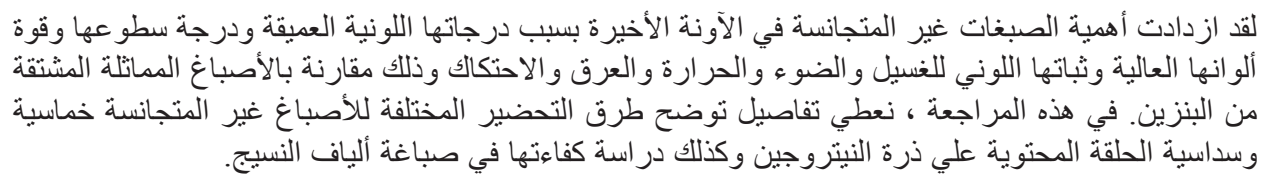

